\title{
Recovery from acute SARS-CoV-2 infection and development of anamnestic immune responses in $\mathbf{T}$ cell-depleted rhesus macaques
}

Kim J. Hasenkrug ${ }^{1 *}$, Friederike Feldmann ${ }^{2}$, Lara Myers $^{1}$, Mario L. Santiago ${ }^{3}$, Kejun Guo ${ }^{3}$, Bradley S. Barrett ${ }^{3}$, Kaylee L. Mickens ${ }^{3}$, Aaron Carmody ${ }^{4}$, Atsushi Okumura ${ }^{5}$, Deepashri Rao ${ }^{1}$, Madison M. Collins ${ }^{1}$, Ronald J. Messer ${ }^{1}$, Jamie Lovaglio² ${ }^{2}$ Carl Shaia ${ }^{2}$, Rebecca Rosenke², Neeltje van Doremalen ${ }^{5}$, Chad Clancy ${ }^{2}$, Greg Saturday², Patrick Hanley ${ }^{2}$, Brian Smith ${ }^{2}$, Kimberly Meade-White ${ }^{5}$, W. Lesley Shupert ${ }^{5}$, David W. Hawman ${ }^{5}$, Heinz Feldmann ${ }^{5}$

${ }^{1}$ Laboratory of Persistent Viral Diseases, Rocky Mountain Laboratories, National Institute of Allergy and Infectious Diseases, National Institutes of Health, Hamilton, MT, USA

${ }^{2}$ Rocky Mountain Veterinary Branch, Rocky Mountain Laboratories, National Institute of Allergy and Infectious Diseases, National Institutes of Health, Hamilton, MT, USA.

${ }^{3}$ Departments of Medicine, Immunology and Microbiology, University of Colorado School of Medicine, Aurora, CO, United States of America

${ }^{4}$ Research Technologies Branch, Rocky Mountain Laboratories, National Institute of Allergy and Infectious Diseases, National Institutes of Health, Hamilton, MT, USA

${ }^{5}$ Laboratory of Virology, Rocky Mountain Laboratories, National Institute of Allergy and Infectious Diseases, National Institutes of Health, Hamilton, MT, USA

*Corresponding author: khasenkrug@nih.gov 


\begin{abstract}
Severe COVID-19 has been associated with $T$ cell lymphopenia ${ }^{1,2}$, but no causal effect of $T$ cell deficiency on disease severity has been established. To investigate the specific role of $\mathbf{T}$ cells in recovery from $\mathrm{SARS}-\mathrm{CoV}-2$ infections we studied rhesus macaques that were depleted of either $\mathrm{CD4}^{+}, \mathrm{CD8}^{+}$or both $\mathrm{T}$ cell subsets prior to infection. Peak virus loads were similar in all groups, but the resolution of virus in the $\mathbf{T}$ cell-depleted animals was slightly delayed compared to controls. The T cell-depleted groups developed virusneutralizing antibody responses and also class-switched to IgG. When re-infected six weeks later, the $\mathbf{T}$ cell-depleted animals showed anamnestic immune responses characterized by rapid induction of high-titer virus-neutralizing antibodies, faster control of virus loads and reduced clinical signs. These results indicate that while $\mathbf{T}$ cells play a role in the recovery of rhesus macaques from acute SARS-CoV-2 infections, their depletion does not induce severe disease, and $\mathbf{T}$ cells do not account for the natural resistance of rhesus macaques to severe COVID-19. Neither primed $\mathrm{CD4}^{+}$or $\mathrm{CD8}^{+} \mathrm{T}$ cells appeared critical for immunoglobulin class switching, the development of immunological memory or protection from a second infection.
\end{abstract}




\section{Introduction}

2 Several lines of evidence suggest that $\mathrm{T}$ cells play important roles in COVID-19 ${ }^{1}$. For example,

3 it has been shown that COVID-19 convalescent patients possess both $\mathrm{CD}^{+}{ }^{+}$and $\mathrm{CD}^{+}{ }^{+} \mathrm{T}$ cells

4 responsive to SARS-CoV-2 antigens ${ }^{3}$. Furthermore, severe COVID-19 is associated with

5 lymphopenia including loss of both $\mathrm{CD}^{+}$and $\mathrm{CD}^{+} \mathrm{T}^{+}$cells ${ }^{4-6}$. However, it is not known whether

6 lymphopenia contributes to severe COVID-19 or is an effect of the disease. Thus, definitive

7 proof of the importance of T cells in recovery from infection and the development of anamnestic

8 responses remains an open question. As an experimental approach to answer this question, we

9 studied adult rhesus macaques that had been depleted of either $\mathrm{CD}^{+}, \mathrm{CD}^{+}$or both $\mathrm{T}$ cell

10 subsets prior to infection with SARS-CoV-2 (Fig. 1a). Similar to most adult humans, rhesus

11 macaques become only mildly or moderately affected following infection with SARS-CoV-2,

12 and they do not normally develop acute respiratory distress syndrome ${ }^{7,8}$. Understanding the

13 immunological mechanisms that participate in the resistance of these animals to severe disease is

14 of great interest because it could lead to the rational design of improved vaccines, prophylactics

15 and therapeutics. In this study we focus on the role of T cells in the resolution of acute SARS-

16 CoV-2 infection, and in the development of immunological memory, which provides better

17 protection upon re-infection. It has been shown that rhesus macaques are protected from re-

18 infection $^{9,10}$, but the role of $\mathrm{T}$ cells and particularly $\mathrm{CD}^{+} \mathrm{T}$ cells in that protection is not yet fully

19 understood $^{11}$. 


\section{Results.}

22 All macaques were inoculated with the Washington isolate of SARS-CoV-2 as previously

23 described $^{7}$ and then rested for six weeks. The animals were then challenged a second time as

24 previously. Two separate experiments were carried out, each with three animals per group for a

25 total of six macaques per group. All results from individual animals are labeled with the same

26 symbol throughout: black symbols for animals in the first experiment and orange for those in the

27 second. Findings from the re-infection are highlighted in yellow throughout.

28 Lymphocyte responses in normal control animals. Most of the non-depleted control animals

29 showed a rapid but transient lymphopenia with loss of $\mathrm{CD}^{+} \mathrm{T}$ helper cells, $\mathrm{CD} 8^{+} \mathrm{T}$ cells and

30 also B cells from the blood, possibly due to homing to lymphoid tissues. CD4 ${ }^{+}$T numbers

31 rebounded to approximately equivalent or higher levels by 7 dpi (Fig. 1b) and CD8 ${ }^{+}$T cell

32 counts were significantly higher at 7 dpi than at day 0 (Fig. 1c) suggesting mobilization or a

33 proliferative response to infection. In support of a proliferative response there was a significant

34 increase in Ki-67 expression at 7 dpi (Supplementary data Fig. 1a). Similar responses were

35 observed following re-infection (yellow shading). B cell numbers in the blood also decreased

36 rapidly after infection and then rebounded over the next several weeks (Fig. 1d).

37 Lymphocyte responses in CD4-depleted animals. At day 0 the $\mathrm{CD}^{+} \mathrm{T}$ cell depletion in the

38 blood was greater than $90 \%$ in all but one animal (\#CD4-5 was 78\% depleted) (Fig. 1e). No

39 significant increases in numbers were observed in the six subsequent weeks suggesting that little

40 or no immunological priming occurred. Most animals showed slight increases in $\mathrm{CD}^{+} \mathrm{T}$ cell

41 counts following re-infection, but it is not known if this was a response to infection or simply

42 reconstitution following depletion (Fig. 1e, yellow shading). The $\mathrm{CD}^{+} \mathrm{T}$ cell responses to

43 infection were quite similar to the controls (Fig. 1f) but there was no B cell response apparent in 
44 the blood except for a minimal response by animal \#CD4-5 following re-infection (Fig. 1f). The

45 reduction of B cell numbers in the CD4-depleted groups compared to the controls over time was

46 statistically significant $(\mathrm{p}=0.0118)$. Thus, depletion of $\mathrm{CD} 4^{+} \mathrm{T}$ cells produced only a minimal

47 impact on $\mathrm{CD}^{+} \mathrm{T}$ cell responses but had a significant negative impact on $\mathrm{B}$ cell responses.

48 Lymphocyte responses in CD8-depleted animals. The expansion of CD4 ${ }^{+} \mathrm{T}$ helpers in the

49 blood following infection in the CD8-depleted animals was similar or slightly stronger than the

50 controls, although one animal (\#CD8-4) failed to respond (Fig. 1h). The CD4 ${ }^{+}$T responses to

51 the second infection also appeared slightly stronger than the controls, possibly a compensatory

52 response to the lack of $\mathrm{CD}^{+} \mathrm{T}$ cells (Fig. $1 \mathrm{~h}$ ). The $\mathrm{CD}^{+} \mathrm{T}$ cell depletions were $>99 \%$ effective

53 in all animals and there was no detectable $\mathrm{CD}^{+} \mathrm{T}$ cell expansion in the blood for the first two

54 weeks after infection suggesting that minimal or no immunological priming had occurred (Fig.

55 1i). There was a slight rebound of $\mathrm{CD}^{+} \mathrm{T}$ cells in most animals by the day of re-infection but

56 little expansion in the following two weeks. Thus, there was no indication of a significant $\mathrm{CD}^{+}$

57 T cell response to either the first or second infection. All but one animal (CD8-4) had B cell

58 expansions as good or better than the controls (Fig. 1j). The non-responding animal started off

59 the experiment with the lowest $\mathrm{CD} 4^{+} \mathrm{T}$ cell count (Fig. 1h), consistent with the finding that

$60 \mathrm{CD}^{+} \mathrm{T}$ cells were important for B cell expansion.

61 Lymphocyte responses in CD4/8 dually-depleted animals. The simultaneous depletions of

62 both $\mathrm{CD}^{+}$and $\mathrm{CD}^{+} \mathrm{T}$ cells were less effective for $\mathrm{CD} 4^{+} \mathrm{T}$ cells than the single subset

63 depletions and ranged between $56 \%$ and $98 \%$ at the time of infection (Fig. 1k). The most

64 strongly depleted animal (\#CD4/8-1) displayed little CD4 ${ }^{+} \mathrm{T}$ cell responsiveness to either the

65 first or second infection. The other five animals showed delayed CD4 ${ }^{+} \mathrm{T}$ cell responses

66 compared to controls, but increased numbers appeared in the 2 to 4 weeks following infection. 
67 Four of the animals showed rapid $\mathrm{CD}^{+} \mathrm{T}$ cell expansion following re-infection indicating that

68 the cells had been primed (Fig. 1k). The CD8 depletions were greater than 99\% effective at 7 dpi

69 (Fig. 11) and both the $\mathrm{CD} 8^{+} \mathrm{T}$ cell responses and B cell responses (Fig. 1m) were very similar to

70 those in the CD8-depleted group. The one animal that failed to make a B cell response was once

71 again the one with the lowest CD4+ $\mathrm{T}$ cell numbers (\#CD4/8-1).

72 Virus loads. As previously described for SARS-CoV-2-infected macaques ${ }^{7,9}$, all animals had

73 high loads of viral RNA in nasal swabs indicative of upper respiratory tract infection. The titers

74 of individual animals in each group are shown in Fig. 2a-d. The RNA loads during the first two

75 weeks of infection were not significantly different between groups, but all control animals

76 cleared infections by 14 days, while the T cell-depleted groups did not totally clear until day 21

77 or later. The dually depleted animals cleared total viral RNA significantly slower than the

78 controls animals $(\mathrm{p}=0.0362$, Fig. $2 \mathrm{~d})$. In all $\mathrm{T}$ cell-depleted groups the second infection was

79 handled better than the first as evidenced by lower viral RNA loads and quicker resolution (Fig.

80 2a-d, yellow shading). To minimize detection of residual inoculum, nasal swabs were also tested

81 for viral E gene subgenomic mRNA (sgRNA) indicative of replicating virus ${ }^{9}$. The mean loads

82 of sgRNA (in blue) were lower than the mean loads of total viral RNA but followed similar

83 curves (Fig. 2e-h). Again, all control animals became undetectable for sgRNA at 7 dpi while all

84 T cell-depleted groups still had positive animals. This delay in virus clearance indicated the

85 involvement of $\mathrm{CD}^{+}$and $\mathrm{CD}^{+} \mathrm{T}$ cells in the rapid resolution of acute infection. However, $\mathrm{T}$

86 cells were not essential for eventual clearance. Viral replication in the lower respiratory tract was

87 assayed by analysis of sgRNA in bronchoalveolar lavages (BAL) at $1 \mathrm{dpi}$ and at 1 day post-re-

88 infection (dpri). At $1 \mathrm{dpi}$, all but one control animal had high viral RNA loads with no

89 significant differences between groups (Fig. 2i-1). Upon re-infection, the lungs showed 
90 significantly reduced viral RNA at 1 dpri (d43) compared to $1 \mathrm{dpi}$, but most animals in all groups

91 had detectable sgRNA in BAL following re-infection. No significant differences between

92 groups were observed at either time point. One or two animals in each group had detectable viral

93 RNA in rectal swabs but no animals had detectable viral RNA in the blood (data not shown). The

94 improved control of virus in the upper and lower respiratory tracts upon re-infection indicated

95 the presence of anamnestic immune responses, and the similarity of all groups in controlling the

96 second infection indicated that such responses were not dependent on an intact $\mathrm{T}$ cell repertoire.

97 We next analyzed clinical signs to determine if the reduced viral loads following re-infection

98 were associated with reduced disease.

99 Clinical signs. On exam days, each animal was scored in a blinded manner for clinical signs and

100 pulmonary radiographs were performed. The most common clinical signs were reduced appetite,

101 slightly irregular abdominal breathing, ruffled fur and pale appearance (Supplementary data Fig.

102 3). The cumulative clinical scores for each animal during the first two weeks of infection and re-

103 infection are shown in Fig. 3a-d. All animals developed mild and transient clinical signs during

104 acute infection, and there were no significant differences between the groups. It cannot be

105 excluded that some of the clinical signs were in response to the procedures performed on the

106 animals, which included anesthesia, blood withdrawals, intratracheal virus inoculation and

107 brocho-alveolar lavage. However, upon re-infection the animals underwent the same procedures,

108 and the mean clinical scores in all groups were significantly reduced compared to primary

109 infection (Fig. 3a-d, yellow shading). Pulmonary radiographs showed that all animals developed

110 minor lesions in at least one lobe of the lungs during the first infection (Fig. 3e-h), and the scores

111 were significantly lower after re-infection except in the CD8-depleted group. There were no

112 statistically significant differences in the radiological findings between the control animals and 
113 the depleted animals at any time points. We thought it was worth noting that all of the control

114 animals and four of six CD4-depleted animals developed a rapid but transient blood neutrophilia

115 following the first but not the second infection (Fig. 3i). Neutrophilia may result from the stress

116 of handling the animals, but no significant neutrophilia was observed following the first infection

117 in either the CD8-depleted or dually depleted animals (Fig. 3k, 1). These findings suggested that

118 neutrophilia was $\mathrm{CD}^{+} \mathrm{T}$ cell-dependent. As a whole, these results indicated that neither CD4 ${ }^{+}$

119 nor $\mathrm{CD}^{+} \mathrm{T}$ cells appeared critical for either recovery from the first infection or improved control

120 of the second infection. Furthermore, there was no evidence that T cell-mediated

121 immunopathology was involved in the disease. The decreased clinical signs following the

122 second infection indicated the induction of an anamnestic immune response that appeared to be

123 largely independent of T cells. Thus, it was of interest to next investigate the antibody

124 responses.

125 Antibody responses. Controls. The development of SARS-CoV-2 receptor binding domain

126 (RBD)-binding antibodies was analyzed in a kinetic manner. The first antibody subtype that

127 develops in response to infections is IgM, and all control animals produced RBD-specific IgM

128 responses peaking at $14 \mathrm{dpi}$ (Fig. 4a). During the antibody maturation process, class switch

129 recombination leads to the development of $\mathrm{IgG}$ isotype antibodies in a process usually dependent

130 on $\mathrm{CD}^{+} \mathrm{T}$ cells. As expected, IgG responses also developed, lagging behind the $\operatorname{IgM}$ responses

131 by one to two weeks and peaking in most animals at 4 wpi (Fig. 4b). The IgG titers had waned

132 slightly by 6 wpi. Upon re-infection, IgG titers rose quickly and dramatically with a mean 37-

133 fold increase in titer within one week (Fig. 4b). All control animals also developed virus-

134 neutralizing antibody $(\mathrm{nAb})$ responses with similar kinetics as the RBD-specific IgG responses

135 (Fig. 1C). These results demonstrated a strong anamnestic antibody response. 
CD4-depleted animals. Half of the CD4-depleted animals showed delayed or flat IgM responses (Fig. 4d) and two of them also showed flat IgG responses until re-infection (Fig. 4e). More

138 surprising was that the other four animals developed class-switched IgG responses and all of

139 them developed both virus-neutralizing responses (Fig. 4f) and strong anamnestic responses

140 upon re-infection (Fig. 4e). Of note, one of the animals in the CD4-depleted group (\#CD4-2)

141 started the experiment with IgM cross-reactive with RBD (Fig. 4d) as did one of the CD8-

142 depleted animals (\#CD8-3). This may have been due to a previous exposure to a different

143 coronavirus. Overall, CD4 depletion delayed and/or dampened IgM and IgG responses in some

144 animals, but all animals developed strong anamnestic IgG responses upon re-infection.

145 CD8 and CD4/8-depleted animals. The IgM, IgG and $\mathrm{A}$ Ab responses of both the CD8- (Fig. 4

$146 \mathrm{~g}-\mathrm{i}$ ) and CD4/8-dually depleted animals (Fig. 4j-1) can be summarized as being very similar to

147 each other and to the controls. No significant effect from CD8-depletions on antibody responses

148 was observed.

149 In summary, there was no major impact of $\mathrm{T}$ cell depletions on the antibody responses even

150 though there was no detectable B cell response in the blood of the CD4-depleted animals (Fig.

151 1g). The binding and neutralizing antibody titers waned by 42 dpi but rapidly expanded upon re-

152 challenge regardless of $\mathrm{T}$ cell depletions. Thus, the memory B cell response may be more

153 critical for protection from re-challenge than standing high titers of antibody.

154 Cervical lymph node analysis. $\mathrm{T}$ cell levels in blood may not reflect levels in tissues where

155 cells may be more refractory to antibody-mediated depletions. No biopsies were taken during the 156 course of the experiment, but immunohistochemical (IHC) staining was used to examine CD4 ${ }^{+}$

157 and $\mathrm{CD}^{+} \mathrm{T}$ cells in necropsy tissues at the termination of the experiment (56 dpi). A 
158 representative section from a cervical lymph node (LN), which drains the upper respiratory tract

159 is shown for each experimental group (Fig. 5).

$160 \mathrm{CD4}^{+} \mathbf{T}$ cells. Sections of cervical lymph nodes (LN) from controls showed abundant CD4 ${ }^{+} \mathrm{T}$

161 cells in periarteriolar lymphoid sheaths and the mantle zone of lymphoid follicles. Representative

162 low and high-magnification sections are shown in Fig. 5a. In comparison, CD4+ T cells were

163 greatly reduced in the lymphoid follicles from CD4-depleted animals, although not completely

164 gone (Fig. 5b). CD4 ${ }^{+} \mathrm{T}$ cell staining appeared normal in the CD8-depleted animals (Fig. 5c), but

165 the CD4/8-depleted animals showed moderately decreased staining (Fig. 5d).

166 Immunohistochemical staining of spleen sections gave results very similar to the cervical lymph

167 nodes (Supplementary data Fig. 5a, b). These findings cannot distinguish between T cells never

168 depleted and re-seeding of the tissues during the course of the experiment.

$169 \mathrm{CD8}^{+} \mathbf{T}$ cells. Compared to the control (Fig. 5e), the CD8 ${ }^{+} \mathrm{T}$ cell staining in the CD4-depleted

170 animals appeared normal to slightly increased (Fig. 5f). The LNs from both the CD8-depleted

171 and dually depleted animals showed dramatically reduced CD8 ${ }^{+}$T cell staining (Fig. 5g, h).

172 B cells. The LN were also stained with anti-CD20 to detect B cells. Unlike the diminished levels

173 of B cells in the blood of CD4-depleted animals (Fig. 1g), no difference in total CD20 staining

174 was observed in the LN (Fig. 5i-1).

175

176 Discussion.

177 It has been previously reported that rhesus macaques infected with SARS-CoV-2 are

178 resistant to severe disease, similar to most young adult humans ${ }^{7}$. In this study we investigated

179 the role of $\mathrm{CD}^{+} \mathrm{T}$ cells in the natural resistance of macaques to severe COVID-19. The

180 relevance of the results is highlighted by the fact that $\mathrm{T}$ cell lymphopenia and $\mathrm{T}$ cell dysfunction 
181 are associated with severe illness in humans with SARS-CoV-2 infection ${ }^{1,2,12}$ 5,13. Interestingly,

182 we found that depletion of either $\mathrm{CD}^{+}$and $\mathrm{CD}^{+} \mathrm{T}$ cells only slightly prolonged the recovery of

183 macaques from a first infection with SARS-CoV-2 and had little or no impact on recovery from

184 re-infection. This is not to say that T cells do not normally play roles in controlling acute SARS-

185 CoV-2 infections or anamnestic responses, but rather that such roles do not appear critical or that

186 their loss may be compensated by other immune cells in macaques. On the other hand, there was

187 also no evidence that $\mathrm{T}$ cells played a pathological role in the development of disease in

188 macaques, as the disease severity in the T cell replete animals was similar to the T cell-depleted

189 animals.

It was unexpected that the CD4-depleted animals would class switch to Ig during primary

191 infection and also mount anamnestic IgG responses upon second infection. The SARS-CoV-2

192 virion does not contain classic T cell-independent antigens, which are typically rigid arrays of 30

193 or more repeated epitopes optimally separated by 5-10 $\mathrm{nm}$ such as those present on vesicular

194 stomatitis virus ${ }^{14} 15$. However, there is evidence that SARS-CoV-2 patients mount

195 extrafollicular B cell responses ${ }^{16,17}$, a type of response that has been shown in mouse studies to

196 produce IgM memory B cells and also IgG class-switched memory B cells in a T cell-

197 independent manner ${ }^{18,19}$. In that regard most of the mice in all of the groups in this study

198 mounted anamnestic IgM responses (Fig. 4 a, d, g, j), and most also produced inflammatory

199 CXCL-10 (Supplementary Fig. 6), a biomarker associated with severe COVID-19 in humans,

200 and also associated with extrafollicular B cells in COVID-19 patients ${ }^{17}$. That said, our analysis

201 did not definitively demonstrate the presence of extrafollicular B cells. We cannot exclude the

202 possibility that despite high level depletions in the blood (Fig. 1d), sufficient CD4+ T cells

203 remained present in lymphoid tissues to generate immunological help. However, the diminished 
204 CD4 staining in cervical lymph nodes at 56 dpi (Fig. 5B) and the strongly ablated B cell

205 responses observed in the blood of the CD4-depleted animals compared to controls (Fig. 1g)

206 argue that the CD4 depletions had a major impact on the T cell repertoire of the animals. B cell

207 activation and stimulation of proliferation typically occur in secondary lymphoid organs where

208 they interact with helper $\mathrm{T}$ cells ${ }^{20}$, but the B cells then disperse and appear in the blood at least

209 transiently, as observed in the control animals but not the CD4-depleted animals (Fig. 1d). It is

210 also possible that help for immunoglobulin class switching was provided by compensatory

211 responses from non-CD4+ cells. For example, in the absence of CD4+ T cells, mouse studies

212 with inactivated influenza virus revealed that $\mathrm{CD}^{-}{ }^{-} \mathrm{CD} 8^{-}$double-negative $\alpha \beta \mathrm{T}$ cells could

213 provide help for immunoglobulin class switching ${ }^{21}$. In addition, interferon gamma-producing $\gamma \delta$

214 T cells have also been shown to enable compensatory immunoglobulin class switching ${ }^{22}$.

215 In McMahan et al. ${ }^{11}$ rhesus macaques previously infected with SARS-CoV-2 were

216 depleted of $\mathrm{CD}^{+} \mathrm{T}$ cells prior to re-infection, which occurred at 7 weeks after the first infection.

217 In that case all 5 of the depleted animals showed breakthrough virus in nasal swabs whereas only

218 one of the controls did. This finding led to the conclusion that $\mathrm{CD}^{+} \mathrm{T}$ cell depletion abrogated

219 the recovery of convalescent macaques. Our study found a slightly prolonged recovery from the

220 first infection but not from re-infection due to $\mathrm{CD} 8^{+} \mathrm{T}$ cell depletion. In our experiments, which

221 employed the same Washington virus isolate and depleting antibody, half of the control animals

222 and half of the CD8-depleted animals showed breakthrough virus in nasal swabs following re-

223 infection as measured by $\operatorname{sgRNA}$ (Fig. 2). Experimental differences included the timing of the re-

224 challenge and the CD8 depletions, as well as the addition of the ocular route of challenge in our

225 experiments. While we found less effect on reinfection than the McMahan study, the difference

226 between these two small studies is not statistically different. Both our studies indicate a role for 
$227 \mathrm{CD}^{+} \mathrm{T}$ cells but a more important role for virus-specific antibodies. It would be of interest in

228 further studies to determine whether T cell immunity in the absence of antibody responses would

229 be sufficient for protection.

230 Old age in humans plays a significant role in susceptibility to severe disease and death

231 from SARS-CoV-2 infections, and it is well known that advanced age is associated with

232 immunosenescence ${ }^{23}$ and dysregulated inflammatory responses ${ }^{24}$ that result in increased

233 vulnerability to infectious diseases. Thus, aged individuals are likely to be considerably less able

234 than adult macaques to compensate for immune deficiencies such as SARS-CoV-2-induced

235 lymphopenia. The oldest macaque in our study was 9 years old, which is not considered to be

236 aged. It has been shown that aged macaques develop lower antibody responses to SARS-CoV-2

237 infections ${ }^{25,26}$, so is possible that different results would have been obtained using aged

238 macaques. That said, our results from adult macaques with profound depletion of either $\mathrm{CD}^{+}{ }^{+}$or

$239 \mathrm{CD}^{+} \mathrm{T}$ cells leads to the conclusion that neither subset played a critical role in their recovery

240 from acute disease or re-infection. On the other hand, anamnestic antibody responses were

241 strongly associated with recovery from a second infection and reduced disease.

242 The current studies do not address the requirement for T cells in long-term memory and

243 protection from COVID-19, which will require further experiments. We are currently faced with

244 the emergence of multiple SARS-CoV-2 variants containing mutations in RBD that allow partial

245 or total escape from monoclonal antibodies and reduce vaccine-induced virus neutralization by

246 antibodies ${ }^{27,28}$. Furthermore, vaccines based on the original spike sequence appear less

247 protective against the new variants, particularly the South African B.1.351 variant. It is not

248 known whether emerging variants are also evolving to escape T cell responses, but the current 
results suggest that there may be less evolutionary pressure to escape $\mathrm{T}$ cell responses than B

250 cell/antibody responses.

Acknowledgements: This work was supported by the Intramural Research Program of the

254 National Institute of Allergy and Infectious Diseases of the National Institutes of Health, USA

255 and by Institutional funds from the Division of Infectious Diseases, University of Colorado AMC

256 (MLS)”. Depleting antibodies were obtained from the Non-human primate Reagent Resource.

257 Many thanks to the Rocky Mountain Labs Veterinary Branch animal caretakers for all their hard

258 work. Thanks to Dan Long for his input on the histology and to Emmie de Wit and Vincent

259 Munster for advice and consultation.

Author Contributions:

262 Author Contributions: KJH contributed to experimental concept, design, data analysis and

263 interpretation, figure preparation, statistical analyses and wrote the paper. HF contributed to

264 experimental design, supervision of animal experiments, interpretation of results and manuscript

265 revision. FF contributed to experimental design and scheduling, performed in vivo and in vitro

266 experiments, animal scoring, collection and preparation of experimental samples and performed

267 necropsies. DR performed viral analyses, cytokine analyses, figure preparation and interpretation

268 of results. RJM performed viral analyses. LM designed and performed flow cytometry

269 experiments and analyses and prepared figures. MS, KG, BSB and KM designed and performed

270 neutralizing antibody assays interpreted results and prepared figures. MMC analyzed plasma for

271 virus-specific antibodies and performed viral analyses. AC collected and prepared samples and

272 designed and performed flow cytometry experiments. AO, JL, and KM-W performed animal 
273 experiments, collected and prepared samples. CS performed necropsies and histological

274 analyses. RR performed immunohistochemical analyses. PH contributed to scheduling

275 experiments, performed clinical exams, necropsies, bloodwork and radiographs.BS performed

276 clinical exams, necropsies, bloodwork and radiographs. NvD contributed to experimental design.

277 CC performed necropsies. GS performed necropsies. WLS contributed to scheduling and

278 logistics. DWH contributed to experimental design.

279

280 Competing Interests: The authors declare no competing interests.

281

282 Materials and Correspondence: Address requests and correspondence to Kim Hasenkrug, email:

283 khasenkrug@nih.gov

285 Materials and Methods

287 Ethics and biosafety statement. All in vivo experiments were performed in accordance with

288 Animal Study Proposal RML 2020-046-E approved by the Institutional Animal Care and Use

289 Committee of Rocky Mountain Laboratories (National Institutes of Health (NIH)) and carried

290 out by certified staff in an Association for Assessment and Accreditation of Laboratory Animal

291 Care International-accredited facility, according to the institution's guidelines for animal use,

292 following the guidelines and basic principles in the NIH Guide for the Care and Use of

293 Laboratory Animals, the Animal Welfare Act, and the United States Department of Agriculture

294 and the United States Public Health Service Policy on Humane Care and Use of Laboratory

295 Animals. Rhesus macaques were housed in adjacent individual primate cages allowing social 
interactions, in a climate-controlled room with a fixed light/dark cycle (12-h light/12-h dark).

297 Commercial monkey chow, treats and fruit were provided twice daily by trained personnel.

298 Water was available ad libitum. Environmental enrichment consisted of a variety of human

299 interaction, manipulanda, commercial toys, videos and music. The Institutional Biosafety

300 Committee (IBC) approved work with infectious SARS-CoV-2 strains under biosafety level 3

301 conditions. Sample inactivation was performed according to IBC-approved standard operating

302 procedures for removal of specimens from high containment.

303 Animals. In the first experiment, 12 adult male rhesus macaques aged $21 / 2$ to 5 yrs. were

304 randomly divided into four groups of three. All animals were euthanized and necropsied on day

30556 (day 14 post re-exposure). The experiment was repeated with a second group of 12 rhesus

306 macaques including 10 females aged 3 to 10 yrs. old and 2 males aged 4 and 5 yrs. old.

307 T cell Depletions. At day -7 (relative to infection) the animals were anesthetized and underwent

308 clinical exams. According to group assignment the macaques received a one-time sq. injection of

309 either 1) (10mg/kg) Rhesus recombinant anti-CD4 depleting antibody (CD4R1), 2) mouse/rhesus

310 CDR-grafted form of the depleting anti-CD8 $\alpha$ antibody, M-T807 (each at 10mg/ml prepared in

311 pharmaceutical grade by the NIH Nonhuman Primate Reagent Resource), 3) both CD4R1 and

312 M-T807 or 4) physiological saline. At days $-4,0$ and +3 the animals received injections as above

313 except via the i.v. route at $5 \mathrm{mg} / \mathrm{kg}$. as per the provider's instructions.

314 Virus Challenges. On days 0 and 42 the animals were anesthetized and inoculated with SARS-

315 CoV-2 by four routes as previously described ${ }^{7}$ : intratracheal $(4 \mathrm{ml})$, intranasal $(0.5 \mathrm{ml}$ each

316 nostril), oral $(1 \mathrm{ml})$ and ocular $(0.25 \mathrm{ml}$ each eye). Back titrations for the inocula showed titers of

$3173.16 \times 10^{5} 50 \%$ tissue culture infectious dose (TCID50)/ml for the first challenge of the first

318 experiment, $4.3 \times 10^{5} \mathrm{TCID} 50 / \mathrm{ml}$ for the second challenge, $4.4 \times 10^{5} \mathrm{TCID} 50 / \mathrm{ml}$ for the first 
challenge of the second experiment and $4.3 \times 10^{5} \mathrm{TCID} 50 / \mathrm{ml}$ for the second challenge of the second experiment. SARS-CoV-2 isolate nCoV-WA1-2020 (MN985325.1)14 (Vero passage 3) was provided by the Centers for Disease Control and Prevention, and propagated as previously

322 described ${ }^{7}$.

323 Clinical Exams and necropsy. Macaques were monitored for clinical signs at least twice daily

324 throughout the experiment using a standardized scoring sheet as previously described ${ }^{7}$. On exam days (Fig. 1A), clinical parameters such as bodyweight, body temperature and respiration rate were collected, as well as ventrodorsal and lateral chest radiographs. Chest radiographs were interpreted in a blinded manner by a board-certified clinical veterinarian. The total white blood

328 cell count, lymphocyte, neutrophil, platelet, reticulocyte and red blood cell counts, and

329 hemoglobin and hematocrit values were determined from EDTA-treated blood using an IDEXX

330 ProCyte DX Analyzer (IDEXX Laboratories). Necropsies were performed after euthanasia and

331 gross pathology was scored by a board-certified veterinary pathologist. Histopathological

332 analysis of tissue slides was performed by a board-certified veterinary pathologist blinded to the 333 group assignment of the macaques.

334 Histology and Immunohistochemistry. Tissues were fixed in $10 \%$ Neutral Buffered Formalin 335 with two changes, for a minimum of 7 days according to IBC-approved SOP. Tissues were 336 processed with a Sakura VIP-6 Tissue Tek, on a 12-hour automated schedule, using a graded 337 series of ethanol, xylene, and PureAffin. Embedded tissues were sectioned at $5 \mu \mathrm{m}$ and dried 338 overnight at $42^{\circ} \mathrm{C}$ prior to staining with hematoxylin and eosin. Specific staining was detected 339 using SARS-CoV/SARS-CoV-2 nucleocapsid antibody (Sino Biological cat\#40143-MM05) at a 340 1:1000 dilution, CD4 antibody (abcam cat\#ab133616) at a 1:100 dilution, CD8 antibody (Sino 341 Biological cat\#10980-T24) at a 1:500 dilution, and CD20 (Thermo Scientific cat\#RB-9013) at a 
1:250 dilution. The tissues were processed for immunohistochemistry using the Discovery Ultra

343 automated stainer (Ventana Medical Systems) with a ChromoMap DAB kit (Roche Tissue

344 Diagnostics cat\#760-159).

345 Morphometric analysis. CD4 and CD8 IHC stained sections were scanned with an Aperio

346 ScanScope XT (Aperio Technologies, Inc., Vista, CA) and analyzed using the ImageScope

347 Positive Pixel Count algorithm (version 9.1). The default parameters of the Positive Pixel Count

348 (hue of 0.1 and width of 0.5 ) detected antigen adequately.

349 Thoracic Radiographs. Ventro-dorsal and right/left lateral radiographs were taken on clinical

350 exam days prior to any other procedures. Radiographs were evaluated and scored for the

351 presence of pulmonary infiltrates by two board-certified clinical veterinarians according to a

352 standard scoring system ${ }^{29}$. Briefly, each lung lobe was scored individually based on the

353 following criteria: $0=$ normal examination; $1=$ mild interstitial pulmonary infiltrates; $2=$

354 moderate interstitial pulmonary infiltrates, perhaps with partial cardiac border effacement and

355 small areas of pulmonary consolidation (alveolar patterns and air bronchograms); and $3=$

356 pulmonary consolidation as the primary lung pathology, seen as a progression from grade 2 lung

357 pathology. Days 0 and 42 radiographs were taken prior to inoculation, and thus serve as a

358 baseline for each animal. As such, scores for all lung lobes on Day 0 were set to " 0 = normal

359 examination." All subsequent radiographs were compared to the Day 0 radiographs, evaluated

360 for changes from baseline and scored based on the criteria noted above. At study completion,

361 thoracic radiograph findings are reported as a single radiograph score for each animal on each

362 exam day. To obtain this score, the scores assigned to each of the six lung lobes are added

363 together and recorded as the radiograph score for each animal on each exam day. Scores

364 therefore range from 0 to 18 for each animal on each exam day. 
365 Spike and RBD-binding IgM and IgG. IgM and IgG titers were quantified from serum

366 collected for all animals on Days 0, 7, 14, 28, 42, and 49. Meso Scale Discovery V-PLEX

367 SARS-CoV-2 Panel 1 Kit (Rockville, MD) was used for determining antibody binding for IgG

368 (K15359U) and IgM (K15360U) specific for SARS-CoV-2 S1 RBD. Protocols were followed as

369 per manufacture's recommendations. All diluted samples fell within standard curve ranges. A

370 Meso Scale Discovery® MESO QuickPlex SQ 120 instrument was used for measuring

371 chemiluminescence with Methodical Minds TM acquisition software. Analysis was performed on

372 the DISCOVERY WORKBENCH® software (version 4.0). Concentrations are relative to

373 internal controls and were reported as arbitrary units/mL (AU/mL). Graphpad Prism 8 was used

374 for preparation of graphs and statistical analysis.

375 Virus-neutralizing antibody assay. Neutralizing antibody titers were determined in plasma

376 samples using a modified lentivirus-based pseudovirion assay ${ }^{30}$. Plasmids encoding an Env-

377 defective HIV-1 backbone tagged with the nanoluciferase gene (HIV-1 ${ }_{\mathrm{NL}} \Delta$ Env-NanoLuc) and

378 an expression construct for the SARS-CoV-2 spike lacking 19 amino acids of the cytoplasmic

379 tail encoding the ER retention motif (CMV-SARS-CoV-2 S $\Delta 19)$ were kind gifts from Dr. Paul

380 Bieniasz (Rockefeller University). Pseudovirions were prepared in HEK293T cells by co-

381 transfecting $60 \mu \mathrm{g}$ of HIV-1 ${ }_{\mathrm{NL}} \Delta$ Env-NanoLuc and CMV-SARS-CoV-2 S $\Delta 19$ at a 3:2 ratio in T-

382175 flasks using the calcium phosphate method, then were concentrated by ultracentrifugation in

383 a sucrose cushion ${ }^{31}$. We utilized A549-ACE2 cells ${ }^{32}$ as target cells as these cells attached better

384 to the culture plate compared to 293T-ACE2 cells ${ }^{30}$, allowing for extensive washes given that

385 the nanoluciferase reporter yielded high backgrounds. A549-ACE2 cells were cultured in

386 complete media containing F-12 Ham's Media (Corning), 10\% fetal bovine serum (Atlanta

387 Biologicals) and 1\% penicillin/streptomycin/glutamine (Corning). For the Nab assay, a 
previously-determined pseudovirus titer $(300,000$ to 400,000 relative light units or RLU per well) were co-incubated with serial 5-fold dilutions of plasma $(1: 5$ to $1: 15,625)$ in $100 \mu 1$ complete media at $37^{\circ} \mathrm{C}$ for $1 \mathrm{~h}$ in 96 -well round-bottom plates. In duplicate, $40 \mu \mathrm{l}$ of the virusplasma mixture was combined with $160 \mu \mathrm{l}$ of complete media containing 10,000 A549-ACE2 cells. The virus-plasma-cell mixtures were plated in white polystyrene plates (Millipore-Sigma) and cultured at $37^{\circ} \mathrm{C} 5 \% \mathrm{CO}_{2}$. After $48 \mathrm{~h}$, the spent media in each well were removed, and the cells were washed four times with $200 \mu 1$ PBS. After the last wash, $100 \mu$ l of PBS was dispensed into each well, and mixed with $100 \mu \mathrm{l}$ of Nano-Glo luciferase substrate working solution (Promega). RLU values were measured in a VictorX5 luminometer (Perkin Elmer). To compute $80 \%$ inhibitory concentrations (IC80), the mean RLUs of virus-only wells $(n=6)$ in each plate were set as $100 \%$ infection. Duplicate RLUs for each plasma dilution were averaged and normalized against virus-only wells. Best-fit nonlinear regression curves were constructed based on a two-phase decay equation (GraphPad Prism 8), and 80\% inhibition values (20\% infection) were interpolated. Nab titers were reported as reciprocal plasma dilutions.

402 Nab titers against live virus were also determined for a subset of plasma samples (28 dpi) in 403 A549-ACE2 cells in a 48-well plate format ${ }^{32}$. Briefly, 1:20, 1:100 and 1:500 dilutions of plasma 404 were co-incubated at $37^{\circ} \mathrm{C}$ for $1 \mathrm{~h}$ with a nonsaturating dose of the SARS-CoV-2 USA-

405 WA1/2020 strain that would yield 100,000 copies in the quantitative PCR assay. After $24 \mathrm{~h}$, 406 virus copy numbers were evaluated from culture supernatant using nucleocapsid-specific primers 407 and probes as we previously described ${ }^{32}$.

408 Virus detection. RNA was extracted from swabs and bronchoalveolar lavage using the QiaAmp 409 Viral RNA kit (Qiagen) according to the manufacturer's instructions and as described ${ }^{7} .5 \mu 1$ 410 RNA was used in a one-step real-time RT-PCR E assay using the Rotor-Gene probe kit (Qiagen) 
411 according to instructions of the manufacturer. In each run, standard dilutions of counted RNA

412 standards were run in parallel, to calculate copy numbers in the samples. For detection of SARS-

413 CoV-2 mRNA, primers targeting open reading frame 7 (ORF7) were designed as follows:

414 forward primer 5'-TCCCAGGTAACAAACCAACC-3', reverse primer 5'-

415 GCTCACAAGTAGCGAGTGTTAT-3', and probe FAM-ZEN-

416 CTTGTAGATCTGTTCTCTAAACGAAC-IBFQ. Five $\mu$ RNA was used in a one-step real-time

417 RT-PCR using the Rotor-Gene probe kit (Qiagen) according to instructions of the manufacturer.

418 In each run, standard dilutions of counted RNA standards were run in parallel, to calculate copy

419 numbers in the samples. Detection of viral E gene subgenomic mRNA (sgRNA) was performed

420 using RT-PCR as described ${ }^{9}$. The forward primer was 5'-3'

421 CGATCTCTTGTAGATCTGTTCTC, the reverse primer was

422 ATATTGCAGCAGTACGCACACA and the probe was

423 FAM-ACACTAGCCATCCTTACTGCGCTTCG-ZEN-IBHQ.

424 Flow Cytometry. Immune cell marker analysis was performed on freshly isolated PBMCs

425 following enrichment after a standard Histopaque 1077 (Sigma) centrifugation procedure in 15-

426 mL Leucosep Tubes (Greiner Bio-One) from EDTA blood samples. Briefly, $3 \mathrm{~mL}$ of room

427 temperature Histopaque 1077 was added to Leucosep tubes and centrifuged at 1000xg for one

428 minute. Blood was diluted 1:2 in 1X DPBS then transferred into the Leucosep tube and

429 centrifuged at $1000 \mathrm{xg}$ for $10 \mathrm{~min}$, RT without the brake. The enriched live PBMC fraction was

430 collected and washed in $1 \mathrm{X}$ DPBS and then transferred into plates for staining. Cells were

431 incubated for 30 min with the following cell surface antibodies: BUV661-anti-CD45 (D058-128,

432 BD Biosciences 741657 Lot 0198214), PE-Cy7-anti-CD20 (2H7, BD Biosciences 560735 Lot

433 0170481), BV786-anti-CD3 (SP34-2, BD Biosciences 563918 Lot 0133645), FITC-anti-CD8 
434 (DK25, Millipore FCMAB176F Lot 3398058), and Pacific Blue-anti-CD4 (OKT4, BioLegend

435317424 Lot B258189) in 2\% FBS PBS supplemented with Brilliant Stain Buffer (BD

436 Biosciences). Intracellular staining was performed using the Foxp3/Transcription Factor Staining

437 Buffer Set (Thermo Fisher) following the company's recommendation. Cells were incubated for

43830 min with the following antibodies: PE-anti-Foxp3 (259D, BioLegend 3202080 Lot B293618)

439 and AF700-anti-Ki-67 (B56, BD Biosciences 561277 Lot 9315354). Live lymphocytes were

440 gated using a SSC-A and FSC-A gate, by FSC-H and FSC-A to exclude doublets and then by

441 time to exclude artifacts caused by erratic sample flow. Gating strategies for B cells and CD8 ${ }^{+}$

442 and $\mathrm{CD}^{+} \mathrm{T}$ cells are shown in Supplementary data Figure 4. The multi-parameter data were

443 collected within the BSL-4 using a Cytoflex LX (Beckman Coulter) and analyzed using FlowJo

444 software (version 10.7.1; TreeStar, Inc).

445 Statistical Analyses. All statistics were analyzed using Prism Mac OS version 8.4.3 software.

446 The specific tests used for statistical analyses are listed in the figure legends. The p value cutoff

447 for statistical significance was set to 0.05. P values are shown in the figures or figure legends. 


\section{References}

1 Chen, Z. \& John Wherry, E. T cell responses in patients with COVID-19. Nat Rev Immunol 20, 529-536, doi:10.1038/s41577-020-0402-6 (2020).

2 Liu, J. et al. Lymphopenia predicted illness severity and recovery in patients with COVID-19: A single-center, retrospective study. PLoS One 15, e0241659, doi:10.1371/journal.pone.0241659 (2020).

3 Grifoni, A. et al. Targets of T Cell Responses to SARS-CoV-2 Coronavirus in Humans with COVID-19 Disease and Unexposed Individuals. Cell 181, 1489-1501 e1415, doi:10.1016/j.cell.2020.05.015 (2020).

4 Giamarellos-Bourboulis, E. J. et al. Complex Immune Dysregulation in COVID-19 Patients with Severe Respiratory Failure. Cell Host Microbe 27, 992-1000 e1003, doi:10.1016/j.chom.2020.04.009 (2020).

5 Diao, B. et al. Reduction and Functional Exhaustion of T Cells in Patients With Coronavirus Disease 2019 (COVID-19). Front Immunol 11, 827, doi:10.3389/fimmu.2020.00827 (2020).

6 Song, C. Y., Xu, J., He, J. Q. \& Lu, Y. Q. Immune dysfunction following COVID-19, especially in severe patients. Sci Rep 10, 15838, doi:10.1038/s41598-020-72718-9 (2020).

7 Munster, V. J. et al. Respiratory disease in rhesus macaques inoculated with SARS-CoV2. Nature 585, 268-272, doi:10.1038/s41586-020-2324-7 (2020).

8 Williamson, B. N. et al. Clinical benefit of remdesivir in rhesus macaques infected with SARS-CoV-2. Nature 585, 273-276, doi:10.1038/s41586-020-2423-5 (2020).

9 Chandrashekar, A. et al. SARS-CoV-2 infection protects against rechallenge in rhesus macaques. Science 369, 812-817, doi:10.1126/science.abc4776 (2020).

10 Deng, W. et al. Primary exposure to SARS-CoV-2 protects against reinfection in rhesus macaques. Science 369, 818-823, doi:10.1126/science.abc5343 (2020).

11 McMahan, K. et al. Correlates of protection against SARS-CoV-2 in rhesus macaques. Nature, doi:10.1038/s41586-020-03041-6 (2020).

12 Mazzoni, A. et al. Impaired immune cell cytotoxicity in severe COVID-19 is IL-6 dependent. J Clin Invest 130, 4694-4703, doi:10.1172/JCI138554 (2020).

13 Gil-Etayo, F. J. et al. T-Helper Cell Subset Response Is a Determining Factor in COVID19 Progression. Front Cell Infect Microbiol 11, 624483, doi:10.3389/fcimb.2021.624483 (2021).

14 Karrer, U. et al. Antiviral B cell memory in the absence of mature follicular dendritic cell networks and classical germinal centers in TNFR1-/- mice. J Immunol 164, 768-778, doi:10.4049/jimmunol.164.2.768 (2000).

15 Hangartner, L., Zinkernagel, R. M. \& Hengartner, H. Antiviral antibody responses: the two extremes of a wide spectrum. Nat Rev Immunol 6, 231-243, doi:10.1038/nri1783 (2006).

16 Newell, K. L. et al. Switched and unswitched memory B cells detected during SARSCoV-2 convalescence correlate with limited symptom duration. PLoS One 16, e0244855, doi:10.1371/journal.pone.0244855 (2021).

17 Woodruff, M. C. et al. Extrafollicular B cell responses correlate with neutralizing antibodies and morbidity in COVID-19. Nat Immunol 21, 1506-1516, doi:10.1038/s41590-020-00814-z (2020). 
18 Allman, D., Wilmore, J. R. \& Gaudette, B. T. The continuing story of T-cell independent antibodies. Immunol Rev 288, 128-135, doi:10.1111/imr.12754 (2019).

19 Di Niro, R. et al. Salmonella Infection Drives Promiscuous B Cell Activation Followed by Extrafollicular Affinity Maturation. Immunity 43, 120-131, doi:10.1016/j.immuni.2015.06.013 (2015).

20 Akkaya, M., Kwak, K. \& Pierce, S. K. B cell memory: building two walls of protection against pathogens. Nat Rev Immunol 20, 229-238, doi:10.1038/s41577-019-0244-2 (2020).

21 Sha, Z. \& Compans, R. W. Induction of CD4(+) T-cell-independent immunoglobulin responses by inactivated influenza virus. $J$ Virol 74, 4999-5005, doi:10.1128/jvi.74.11.4999-5005.2000 (2000).

22 Maloy, K. J., Odermatt, B., Hengartner, H. \& Zinkernagel, R. M. Interferon gammaproducing gammadelta $\mathrm{T}$ cell-dependent antibody isotype switching in the absence of germinal center formation during virus infection. Proc Natl Acad Sci U S A 95, 11601165, doi:10.1073/pnas.95.3.1160 (1998).

23 Aiello, A. et al. Immunosenescence and Its Hallmarks: How to Oppose Aging Strategically? A Review of Potential Options for Therapeutic Intervention. Front Immunol 10, 2247, doi:10.3389/fimmu.2019.02247 (2019).

24 Frasca, D. \& Blomberg, B. B. Inflammaging decreases adaptive and innate immune responses in mice and humans. Biogerontology 17, 7-19, doi:10.1007/s10522-015-9578-8 (2016).

25 Singh, D. K. et al. Responses to acute infection with SARS-CoV-2 in the lungs of rhesus macaques, baboons and marmosets. Nat Microbiol 6, 73-86, doi:10.1038/s41564-02000841-4 (2021).

26 Yu, P. et al. Age-related rhesus macaque models of COVID-19. Animal Model Exp Med 3, 93-97, doi:10.1002/ame2.12108 (2020).

27 Wang, Z. et al. mRNA vaccine-elicited antibodies to SARS-CoV-2 and circulating variants. bioRxiv, doi:10.1101/2021.01.15.426911 (2021).

28 Wang, P. et al. Antibody Resistance of SARS-CoV-2 Variants B.1.351 and B.1.1.7. Nature, doi:10.1038/s41586-021-03398-2 (2021).

29 Brining, D. L. et al. Thoracic radiography as a refinement methodology for the study of $\mathrm{H} 1 \mathrm{~N} 1$ influenza in cynomologus macaques (Macaca fascicularis). Comp Med 60, 389395 (2010).

30 Schmidt, F. et al. Measuring SARS-CoV-2 neutralizing antibody activity using pseudotyped and chimeric viruses. J Exp Med 217, doi:10.1084/jem.20201181 (2020).

31 Dillon, S. M., Guo, K., Castleman, M. J., Santiago, M. L. \& Wilson, C. C. Quantifying HIV-1-Mediated Gut CD4(+) T Cell Deathin the Lamina Propria Aggregate Culture (LPAC) Model. Bio Protoc 10, e3486, doi:10.21769/BioProtoc.3486 (2020).

32 Guo, K., Barrett, B. S., Mickens, K. L., Hasenkrug, K. J. \& Santiago, M. L. Interferon Resistance of Emerging SARS-CoV-2 Variants. bioRxiv, doi:10.1101/2021.03.20.436257 (2021). 


\section{Figures}

$\mathbf{a}$

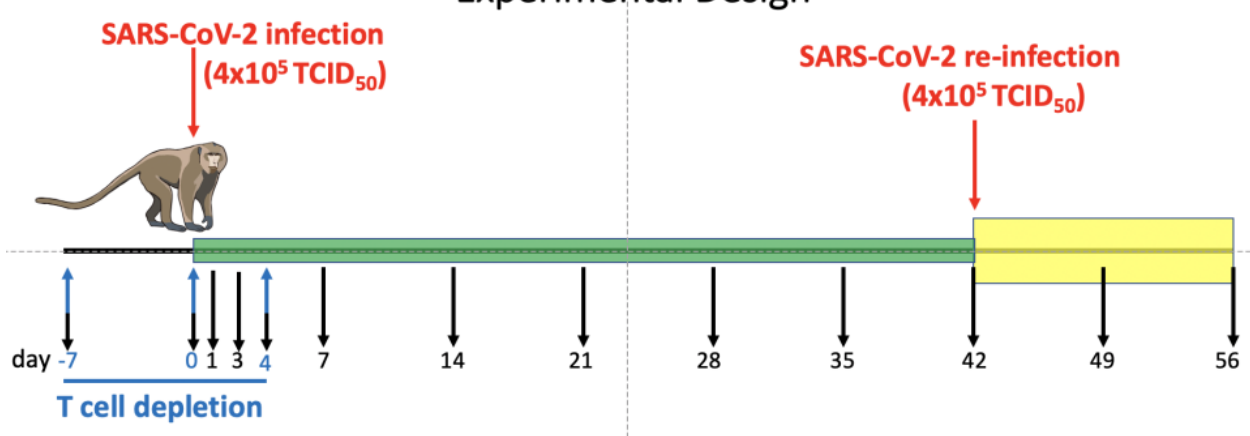

$\downarrow$ Clinical exams, nasal swabs, blood withdrawals, radiographs, hematology, Flow cytometry
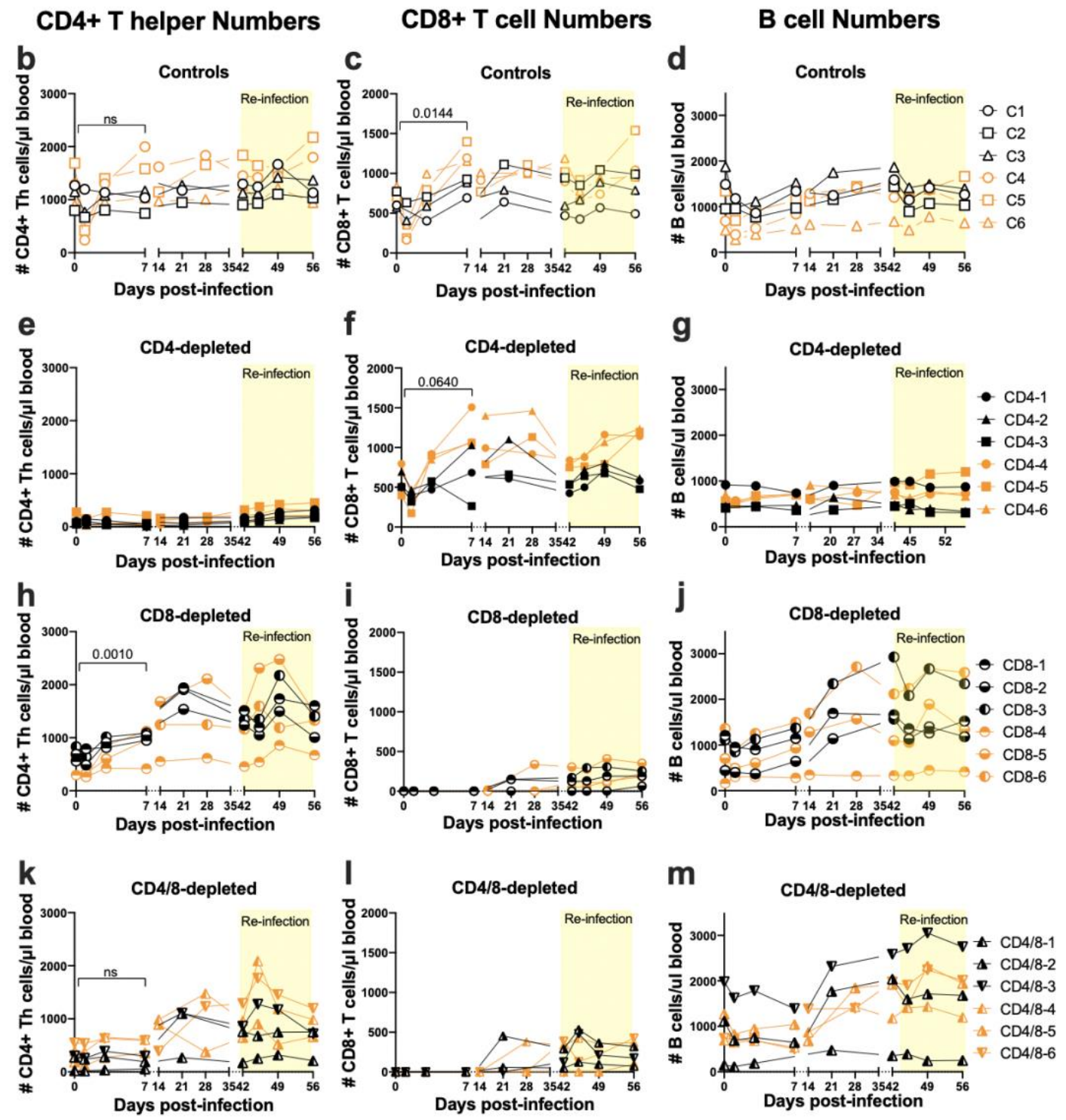


\section{Figure 1}

Figure 1. Experimental design and $\mathbf{T}$ cell depletions. a. $\mathrm{T}$ cell subset-depleting antibodies were administered on days $-7,0$ and +4 as indicated by the blue arrows. Infections were done on days 0 and 42 as indicated by red arrows. Blood withdrawals were performed on the days indicated by the black arrows and flow cytometry was used to determine the lymphocyte subset numbers over time. The flow cytometry gating strategies are shown in Supplemental data Fig. 1b. Each symbol represents a single animal throughout. All CD4-depleted animals except CD45 were still greater than $90 \%$ depleted of $\mathrm{CD}^{+}$T cells at $7 \mathrm{dpi}$. CD4-5 was $78 \%$ depleted. CD4+ Th numbers excluded FoxP $3^{+}$cells. At 7 days post-re-infection (49 dpi) the animals averaged $81 \%$ depleted. All CD8-depleted animals were $>99 \%$ depleted at $7 \mathrm{dpi}$ and remained $78 \%$ depleted at 49dpi. The differences between subset numbers at 0 dpi and 7 dpi were calculated by a two-way paired $t$ test. $n s=$ not significant and other $\mathrm{p}$ values are shown. Numbers of $\mathrm{B}$ cells (d, g, j, m) were determined by flow cytometry using CD45 and CD20 as markers. The numbers of B cells in the CD4-depleted group were significantly lower over time than the controls as determined by mixed effects analysis $(\mathrm{p}=0.0118)$. 

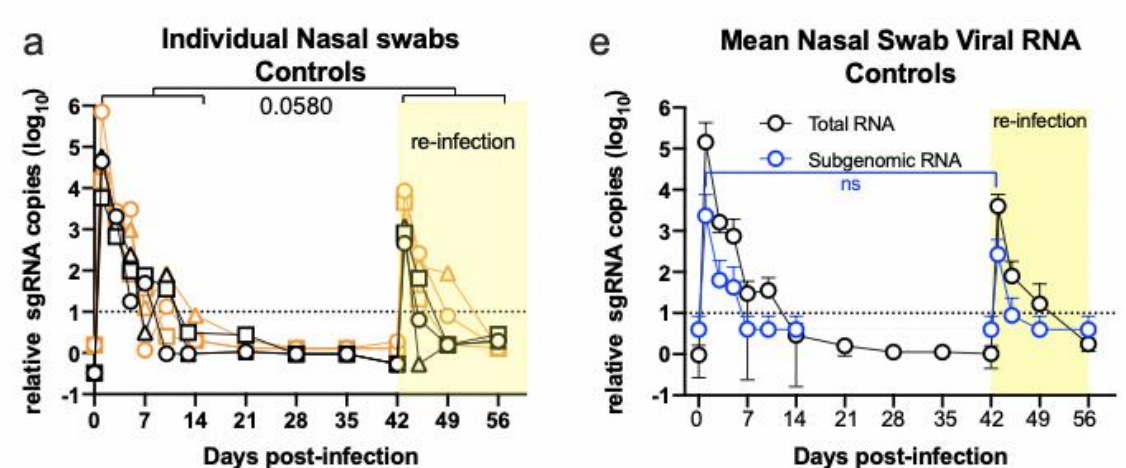

b Individual Nasal swabs
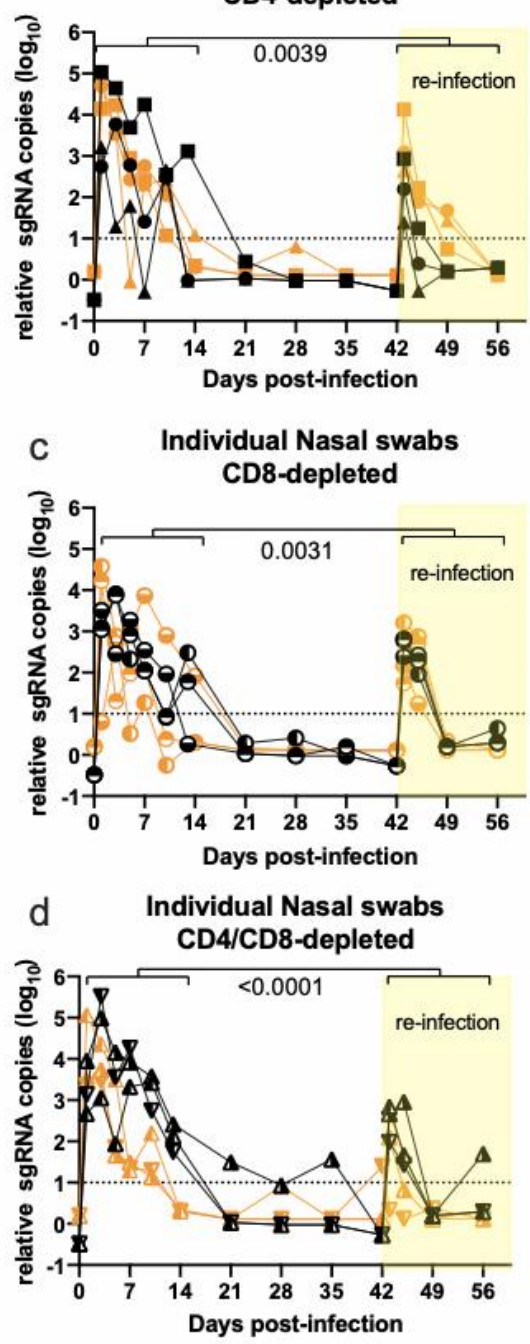
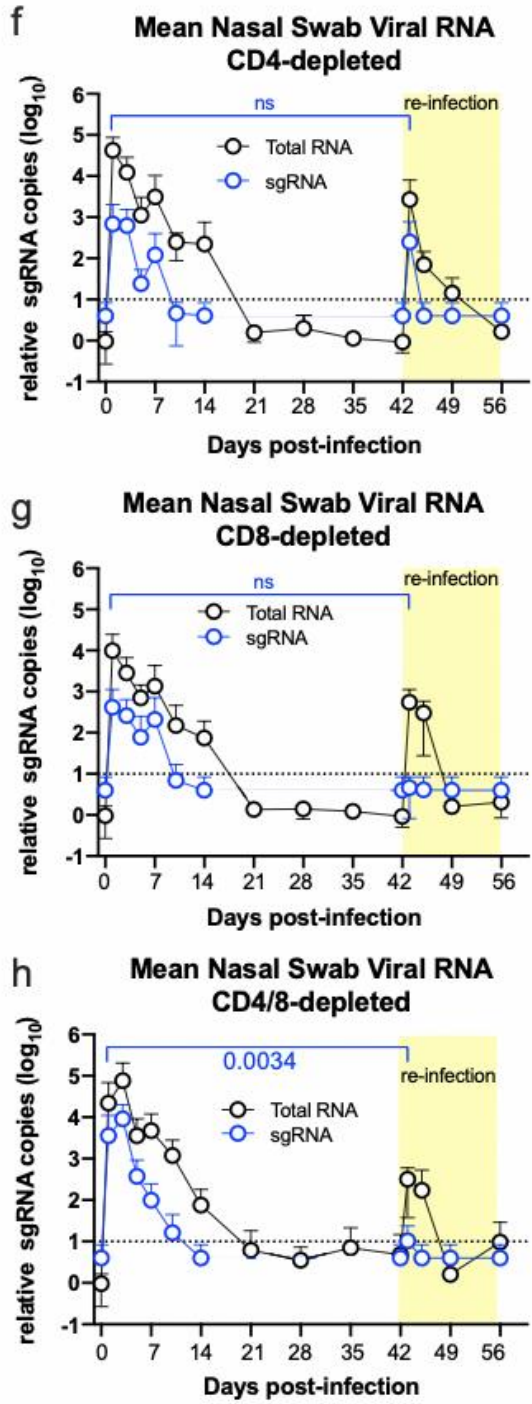

BAL

Controls

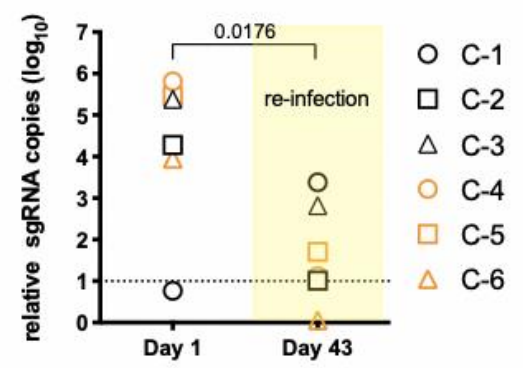

BAL

CD4-depletion

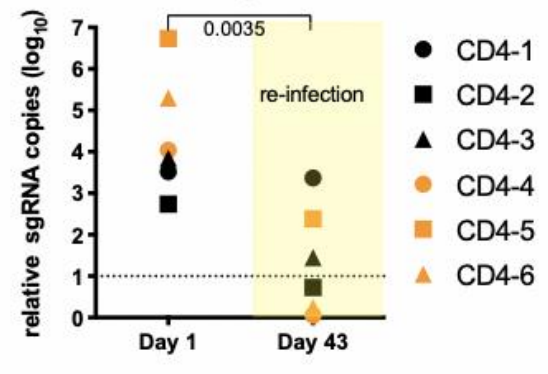

BAL

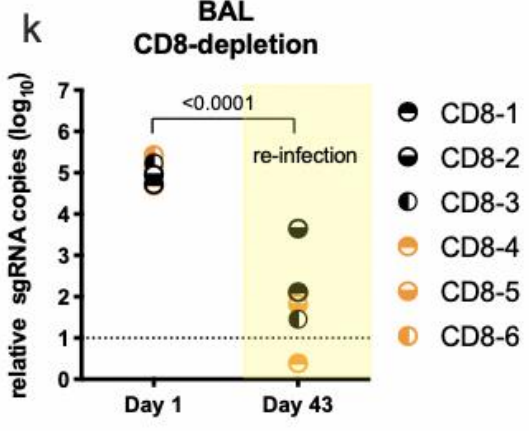

BAL

CD4/CD8-depletion

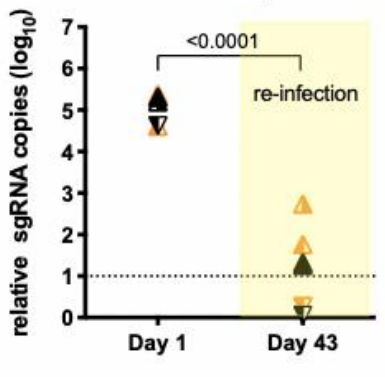

$\triangle \mathrm{CD} 4 / 8-1$

$\Delta \mathrm{CD} 4 / 8-2$

v $C D 4 / 8-3$

CD4/8-4

CD4/8-5

CD4/8-6 
Figure 2. Virus detection from nasal swabs and Broncho-alveolar lavages. (a-d) Each symbol represents the value of viral RNA copies from an individual animal at each time point. The brackets delineate comparisons of cumulative values between the first two weeks after infection with the two weeks after re-infection, and numbers indicate the $p$ values from two-way paired t tests showing significantly reduced virus levels following the second infection (b, c, d) except in the control group (a), which was marginally non-significant. The cumulative RNA titers from the CD4- and CD8-depleted groups for the first two weeks after initial infection were not significantly different than the controls but the CD4/CD8-depleted group had significantly higher titers $(\mathrm{p}=0.0362$ by one-way Anova with a Dunnett's post-test). $\mathrm{b}$ In $(\mathrm{e}-\mathrm{h})$ mean values are shown comparing the total viral RNA data from a -d (black lines) with sub-genomic sgRNA results (blue lines). (i-l) Broncho-alveolar lavage fluids were taken at one day after infection and re-infection. sgRNA was measured from each animal and showed significantly reduced virus replication upon second infection ( $\mathrm{p}$ values from paired $\mathrm{t}$ tests shown in figure). 
a

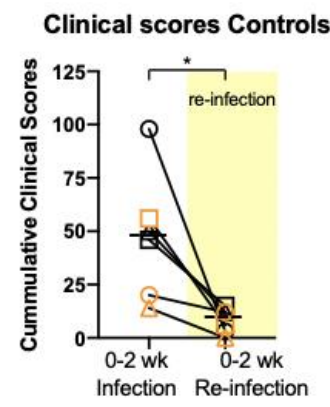

b Clinical scores CD4-depleted

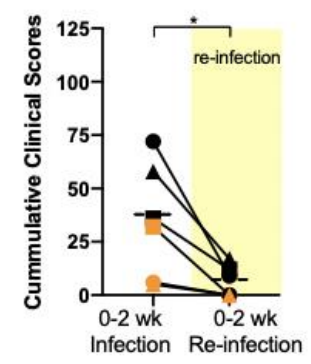

C Clinical scores CD8-depleted

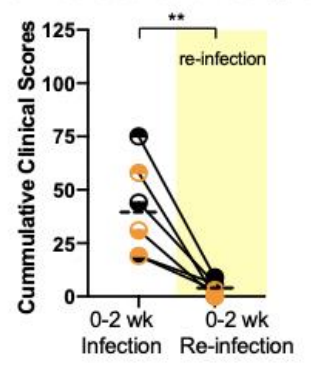

d Clinical scores CD4/CD8-depleted

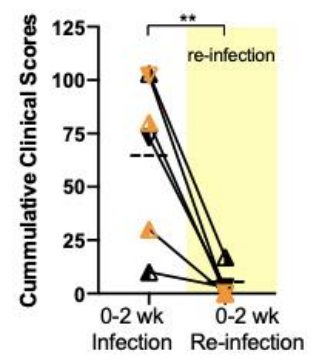

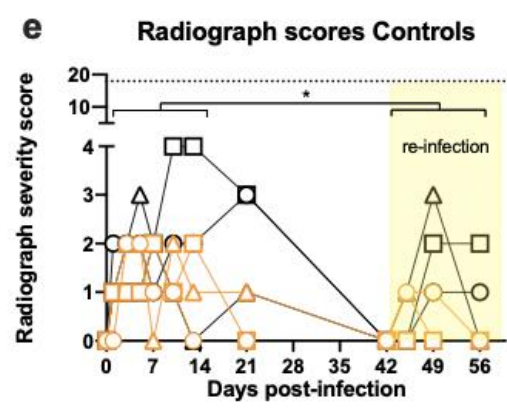

i
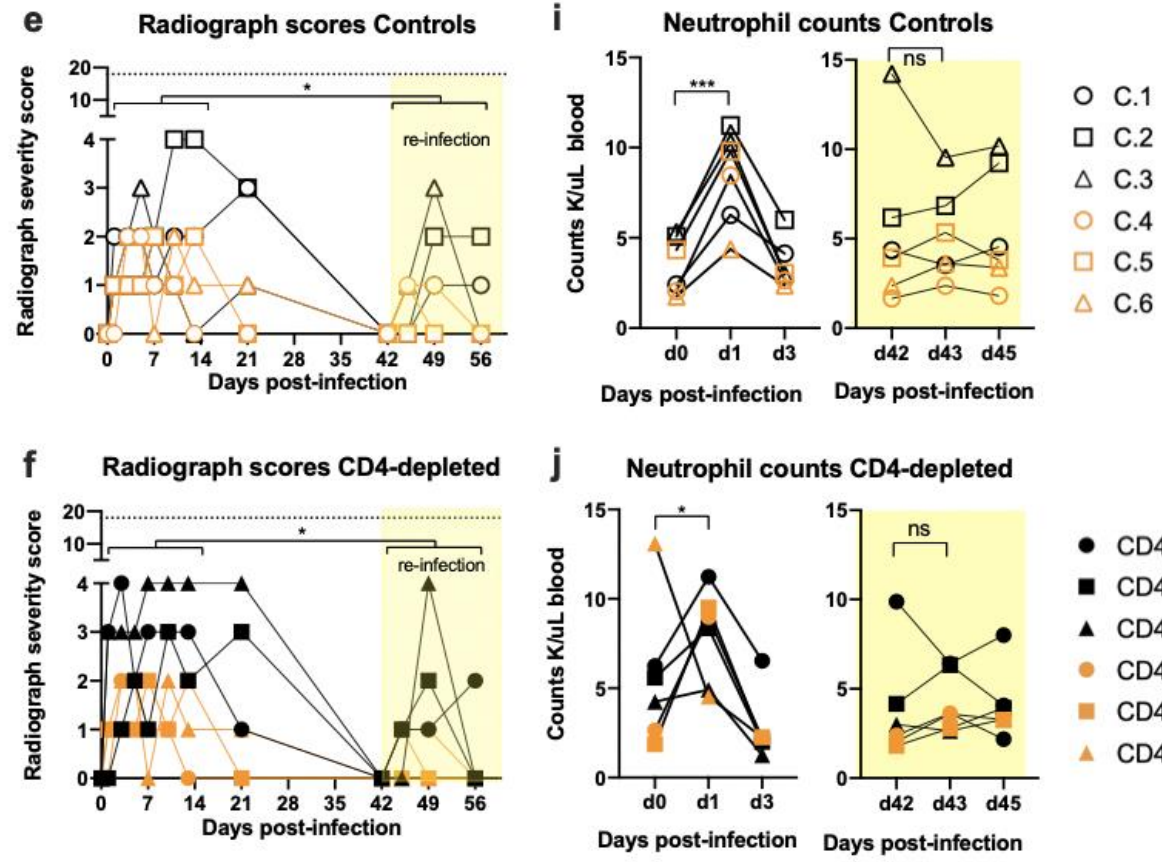

- CD4-1

- $\mathrm{CD} 4-.2$

$\Delta \mathrm{CD} 4-3$

- CD4-.4

- CD4-.5

$\triangle$ CD4-6

K Neutrophil Counts CD8-depleted
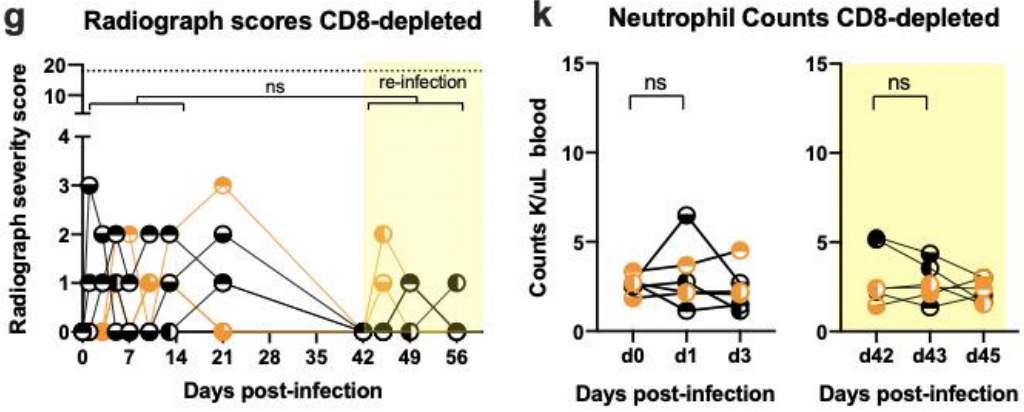

- CD8-1

- CD8-2

- $\mathrm{CD} 8-3$

๑ CD8-4

๑ CD8-.5

(1) CD8-6

Neutrophil counts CD4/8-depleted

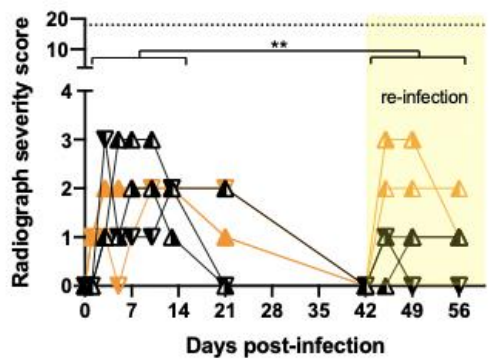

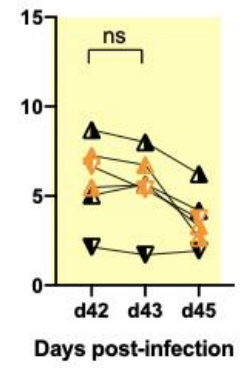

$\triangle \mathrm{CD} 4 / 8-1$

$\Delta \mathrm{CD} 4 / 8-.2$

v $\mathrm{CD} 4 / 8-.3$

$\triangle \mathrm{CD} 4 / 8-.4$

$\triangle \mathrm{CD} 4 / 8-.5$

$\nabla$ CD $4 / 8-.6$

Figure 3. Clinical and radiograph scores and neutrophil counts. (a -d) Clinical signs were scored in a blinded manner using a clinical score sheet. Cumulative scores for the two weeks following the first infection were compared with the two weeks following re-infection (yellow shading) using a two-way paired Student's $t$ test. The dashed lines indicate means. (e $-\mathrm{h}$ ) Radiographs were scored in a blinded manner for the presence of pulmonary infiltrates by two board-certified clinical veterinarians. Cumulative scores were analyzed as in a-d. The dotted line indicates the maximum score if all lobes were severely affected. ( $\mathrm{i}-\mathrm{l}$ ) Neutrophil counts for each animal were taken on blood withdrawal days and significant differences were noted only between days 0 to 3 as shown. $\mathrm{ns}=$ not significant, $*=\mathrm{p}<0.05, * *=\mathrm{p}<0.01, * * *=\mathrm{p}<0.001$. 

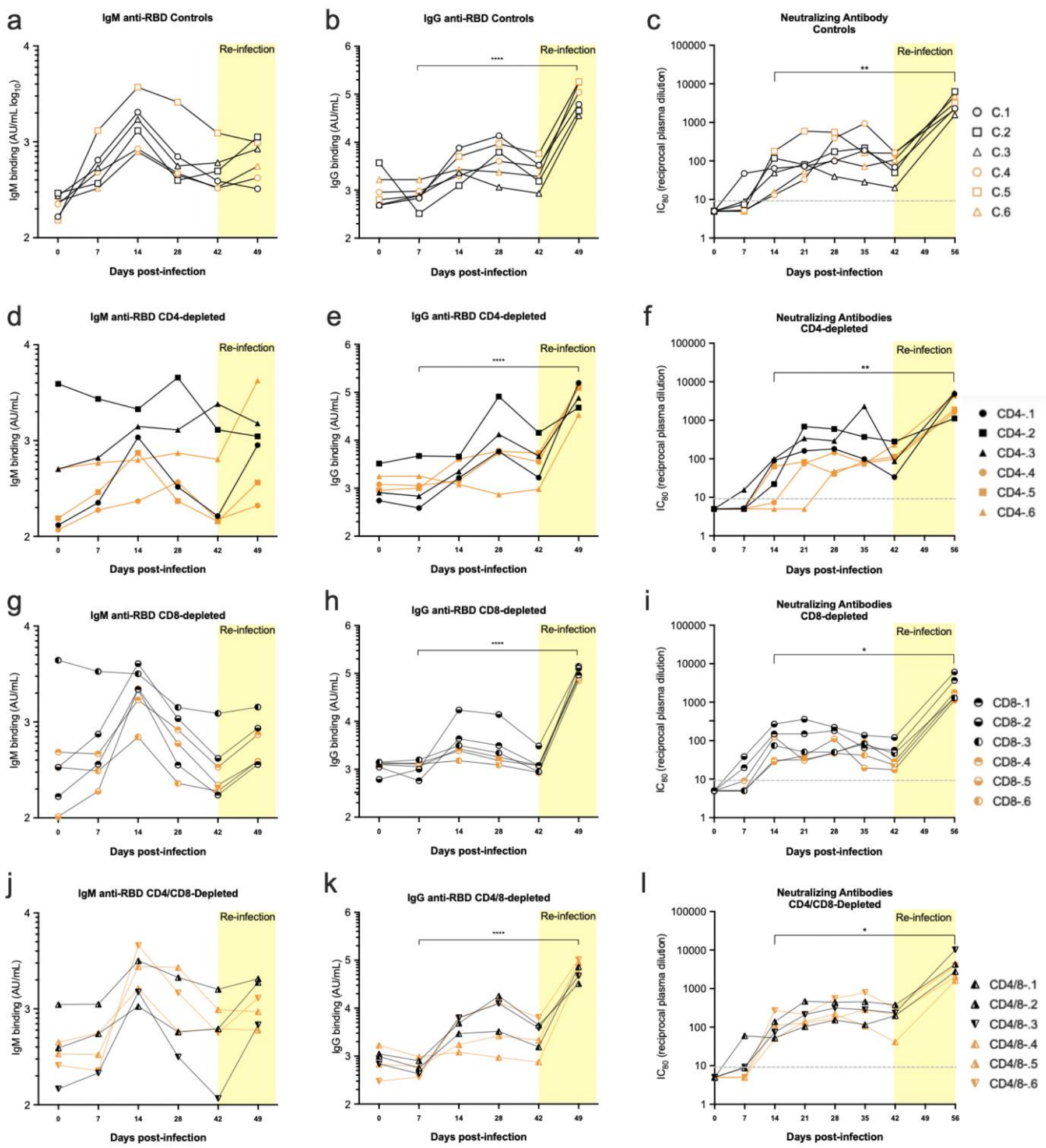

Figure 4. Antibody responses. SARS-CoV-2 spike receptor binding domain-specific IgM (a, $\mathrm{d}, \mathrm{g}, \mathrm{j}$ ) and $\mathrm{IgG}$ responses (b, e, h, k) were assayed in individual macaques over the course of the experiment using the Mesoscale kit as described in the methods. Each symbol represents a specific animal throughout. Neutralizing antibody titers (c, f, I, l) were measured using a 
lentiviral pseudovirus expressing the human SARS-CoV-2 spike as described in the method section. Values are reciprocal dilutions that produced an $80 \%$ reduction in pseudovirus infection (c, f, i, 1). Statistics comparing titers at days 7 dpi and 49 dpi were done using a two-way paired Student's t test $*=\mathrm{p}<0.05, * * * *=\mathrm{p}<0.0001$. Unlabeled comparisons were not statistically significant. Analysis of differences between experimental groups was done by one-way Anova with a Dunnett's multiple comparisons post-test. The ability of sera from 28 dpi to neutralize live SARS-CoV-2 confirmed results from the pseudovirus neutralization assay (Supplemental data Fig. 4). 

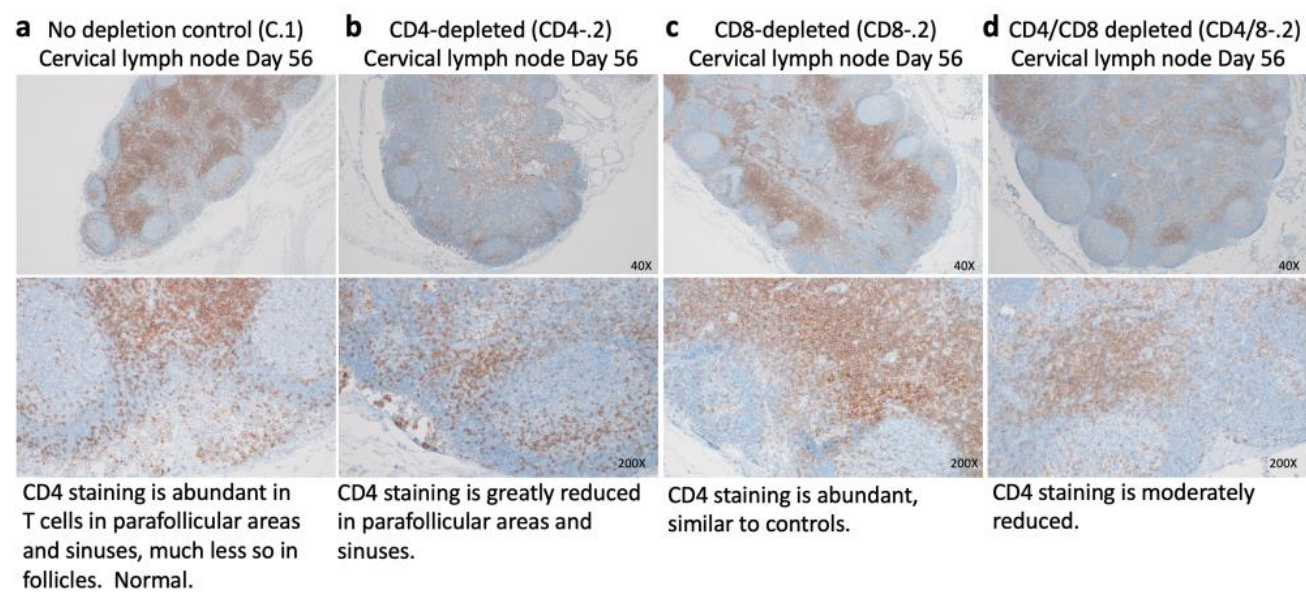
follicles. Normal.
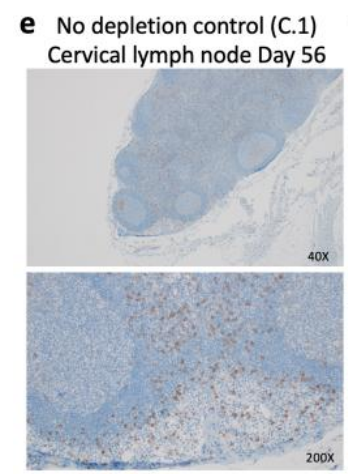

CD8 staining is present in subcapsular sinuses, mantle and marginal zones between lymphoid follicles. Normal.

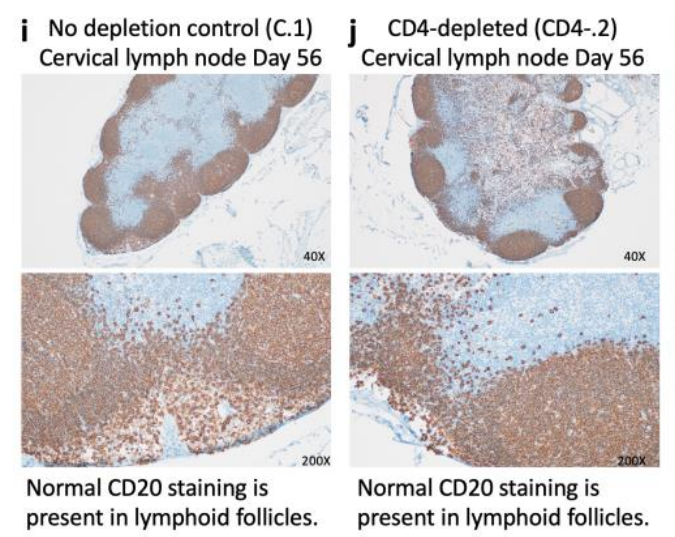

f CD4-depleted (CD4-.2) Cervical lymph node Day 56
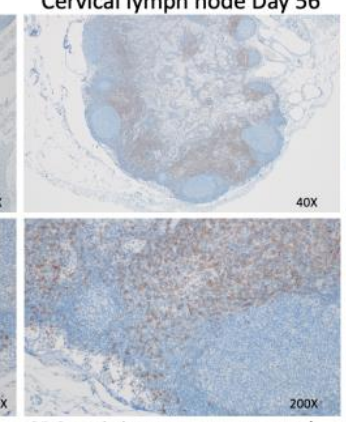

CD8 staining appears normal to moderately increased.

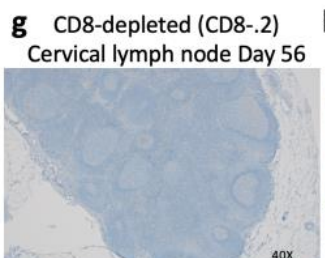

h CD4/CD8 depleted (CD4/8-.2) Cervical lymph node Day 56

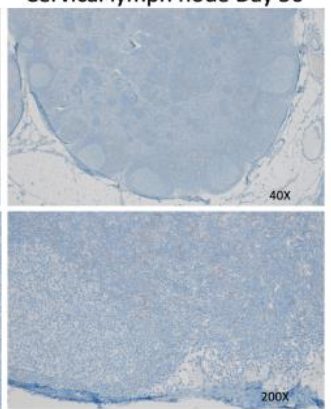

CD8 staining is greatly reduced $\mathrm{CD} 8$ staining is greatly reduced throughout the node. throughout the node.

Figure 5. Immunohistochemical staining of cervical lymph nodes for CD4+ and CD8+ T cells and $B$ cells. Representative animals from each experimental group are shown. $(a-d)$ Cervical lymph nodes stained with anti-CD4 antibodies. $(\mathrm{e}-\mathrm{h})$ Cervical lymph nodes stained with anti-CD8 antibodies. ( $\mathrm{i}-1)$ Cervical lymph nodes stained with anti-CD20 antibodies to detect B cells. None of the tissues stained positive for the presence of SARS-CoV-2 at 56 dpi. 


\section{Supplementary data Fig. 1a. Ki-67 staining of CD8+ T cells}

\section{$\underline{\mathrm{Ki}-67+\mathrm{CD} 8+\mathrm{T} \text { cell Numbers }}$}
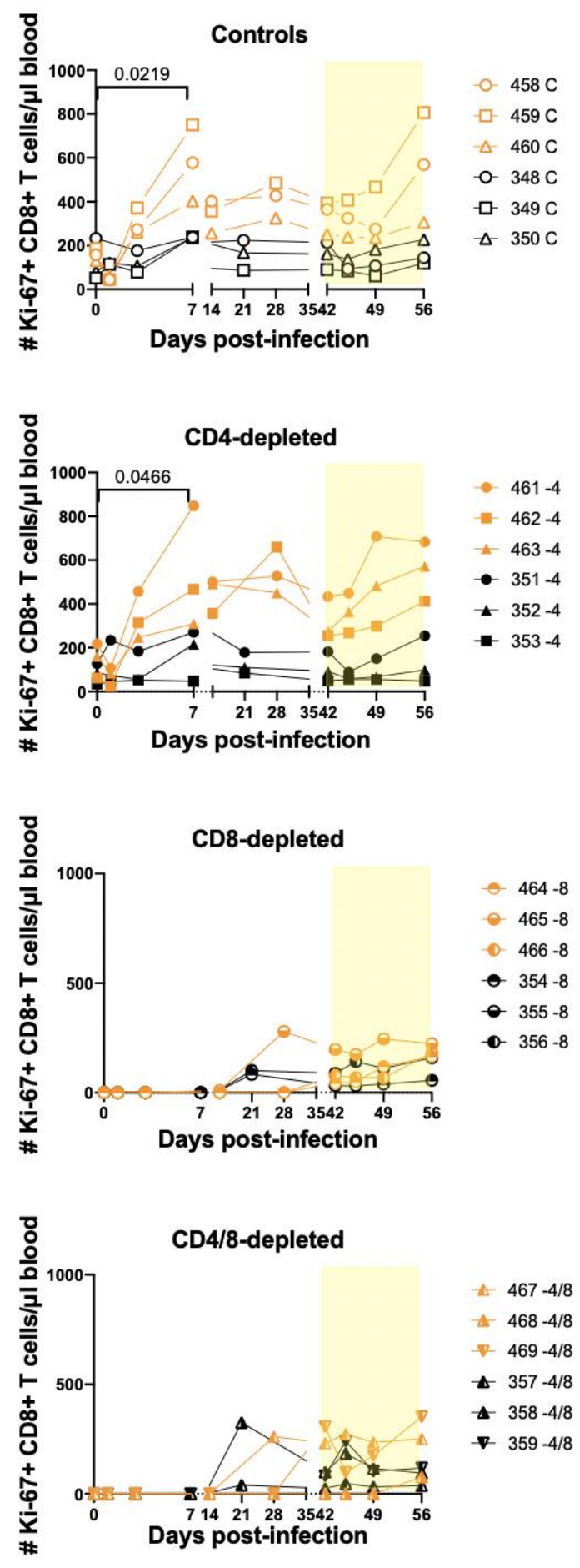


\section{Supplementary data Fig. 1b. Gating strategies for Flow Cytometry.}

\section{a. Gating Strategy for CD4+ T cells}
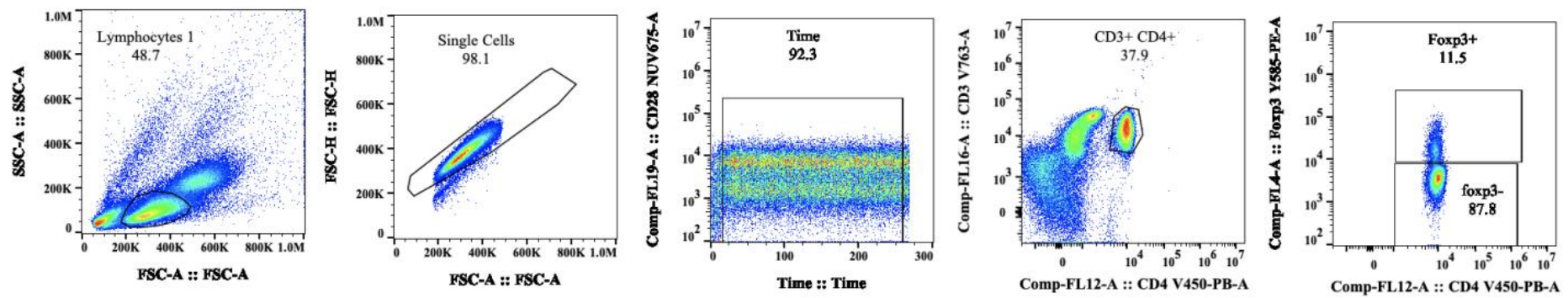

\section{b. Gating Strategy for CD8+ T cells}
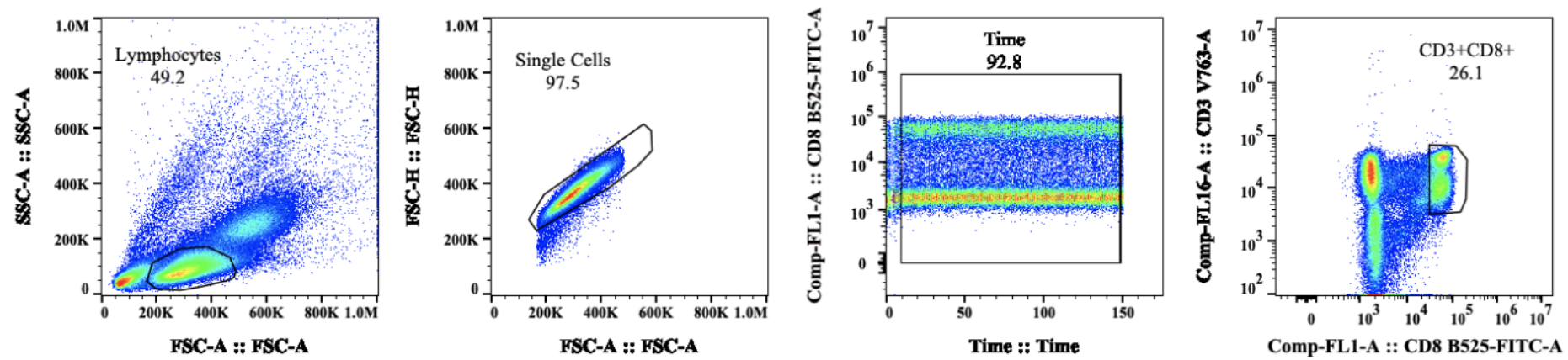

\section{c. Gating strategy for B cells}
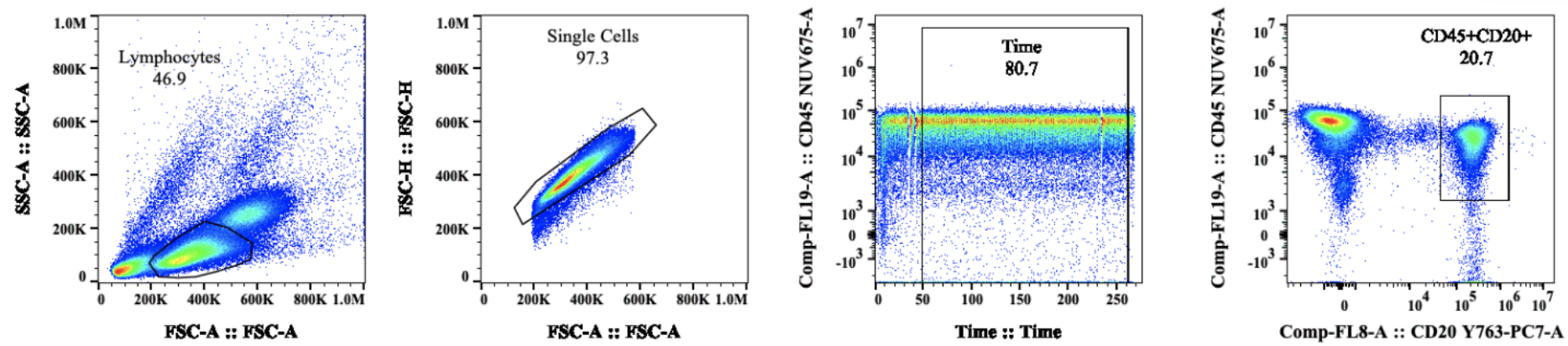


\section{Supplementary data Fig. 3}

\section{Clinical data n- CoV 2019 CoV 348-359}

\begin{tabular}{|c|c|c|c|}
\hline $\begin{array}{l}\text { Animal } \\
\text { ID }\end{array}$ & Day $0-13$ & Day $42-56$ & Necropsy notes \\
\hline C-1 & $\begin{array}{l}\text { Hunched posture, ruffled fur, pale } \\
\text { appearance, increased irregular respirations } \\
\text { Score:3/5/5/10/10/10/10/10/10/5/5/5/5/5/0 } \\
\text { (98) }\end{array}$ & $\begin{array}{l}\text { Reduced appetite } \\
\text { Score: } \\
\text { 3/0/0/0/0/0/0/0/0/0/0/0/0/0/0/0/0 (3) }\end{array}$ & normal \\
\hline $\mathrm{C}-2$ & $\begin{array}{l}\text { Reduced appetite, abdominal breathing, pale } \\
\text { appearance } \\
\text { Score :3/5/3/3/3/3/5/3/3/3/3/3/3/3/0 (46) }\end{array}$ & $\begin{array}{l}\text { Reduced appetite } \\
\text { Score: } 3 / 3 / 3 / 3 / 3 / 0 / 0 / 0 / 0 / 0 / 0 / 0 / 0 / 0(15)\end{array}$ & normal \\
\hline C-3 & $\begin{array}{l}\text { Reduced appetite, slightly irregular } \\
\text { respirations } \\
\text { Score: } 3 / 3 / 8 / 3 / 3 / 5 / 5 / 8 / 3 / 0 / 3 / 3 / 0 / 3 / 0(50)\end{array}$ & $\begin{array}{l}\text { Reduced appetite } \\
\text { Score:3/3/3/0/3/0/0/0/0/0/0/0/0/0 (12) }\end{array}$ & Right lung: adhe \\
\hline CD4-1 & $\begin{array}{l}\text { Reduced appetite, increased abdominal } \\
\text { respirations, pale appearance } \\
\text { Score: } 0 / 8 / 8 / 8 / 8 / 8 / 5 / 5 / 8 / 5 / 5 / 0 / 2 / 2 / 0(72)\end{array}$ & $\begin{array}{l}\text { Reduced appetite, slightly irregular } \\
\text { respirations } \\
\text { Score: } 0 / 3 / 2 / 2 / 2 / 0 / 0 / 0 / 0 / 0 / 0 / 0 / 0 / 0(9)\end{array}$ & Lung FTC (BAL) \\
\hline CD4-2 & $\begin{array}{l}\text { Reduced appetite } \\
\text { Score: } 3 / 3 / 3 / 3 / 3 / 3 / 3 / 3 / 3 / 0 / 3 / 3 / 3 / 0 / 0 \text { (36) }\end{array}$ & $\begin{array}{l}\text { Reduced appetite } \\
\text { Score:3/3/3/3/3/0/0/0/0/0/0/0/0/0/0 } \\
(12)\end{array}$ & normal \\
\hline CD4-3 & $\begin{array}{l}\text { Reduced appetite, increased irregular } \\
\text { respirations } \\
\text { Score:0 /8/8/10/8/3/5/5/3/3/0/3/0/2/0 (58) }\end{array}$ & $\begin{array}{l}\text { Reduced appetite, slightly irregular } \\
\text { respirations } \\
\text { Score:0/5/5/2/5/0/0/0/0/0/0/0/0/0/0 } \\
\text { (17) }\end{array}$ & normal \\
\hline CD8-1 & $\begin{array}{l}\text { Reduced appetite, increased abdominal } \\
\text { respirations } \\
\text { Score:0/8/10/8/8/8/8/8/8/3/3/3/0/0 (75) }\end{array}$ & $\begin{array}{l}\text { Reduced appetite } \\
\text { Score: } 0 / 3 / 3 / 0 / 0 / 0 / 0 / 0 / 0 / 0 / 0 / 0 / 3 / 0 / 0 \\
\text { (9) }\end{array}$ & normal \\
\hline CD8-2 & $\begin{array}{l}\text { Reduced appetite, increased abdominal } \\
\text { respirations } \\
\text { Score:3/8/8/8/5/3/0/3/0/0/3/3/0/0/0 (44) }\end{array}$ & $\begin{array}{l}\text { Reduced appetite } \\
\text { Score: } 3 / 3 / 0 / 0 / 0 / 0 / 0 / 0 / 0 / 0 / 0 / 0 / 0 / 0 \\
(6)\end{array}$ & Mediastinal LN \\
\hline CD8-3 & $\begin{array}{l}\text { Reduced appetite, slightly irregular } \\
\text { respirations } \\
\text { Score: } 0 / 3 / 2 / 5 / 2 / 2 / 2 / 0 / 3 / 0 / 0 / 0 / 0 / 0 / 0 \text { (19) }\end{array}$ & $\begin{array}{l}\text { Reduced appetite } \\
\text { Score:0/3/3/0/0/0/0/0/0/0/0/0/0/0 } \\
\text { (6) }\end{array}$ & normal \\
\hline CD4/8-1 & $\begin{array}{l}\text { Slightly irregular abdominal respirations } \\
\text { Score: } 0 / 0 / 0 / 0 / 0 / 2 / 2 / 2 / 2 / 0 / 2 / 0 / 0 / 0 / 0(10)\end{array}$ & $\begin{array}{l}\text { Reduced appetite } \\
\text { Score:0/0/3/0/0/0/0/0/0/0/0/0/0/0 } \\
\text { (3) }\end{array}$ & normal \\
\hline CD4/8-2 & $\begin{array}{l}\text { Reduced appetite, hunched posture, ruffled } \\
\text { fur, increased irregular abdominal } \\
\text { respirations, nasal discharge } \\
\text { Score: } 3 / 3 / 8 / 13 / 13 / 13 / 13 / 8 / 8 / 5 / 5 / 5 / 2 / 2 / 0 \\
\text { (103) }\end{array}$ & $\begin{array}{l}\text { Reduced appetite, increased abdominal } \\
\text { respirations } \\
\text { Score: } 0 / 3 / 2 / 2 / 8 / 0 / 0 / 0 / 2 / 0 / 0 / 0 / 0 / 0 \\
\text { (17) }\end{array}$ & normal \\
\hline
\end{tabular}




\begin{tabular}{|l|l|l|l|}
\hline CD4/8-3 & $\begin{array}{l}\text { Reduced appetite, increased irregular } \\
\text { respirations, pale appearance } \\
\text { Score: } 3 / 8 / 7 / 8 / 8 / 5 / 5 / 8 / 8 / 5 / 5 / 3 / 0 / 0 / 0 / 0 ~(73)\end{array}$ & $\begin{array}{l}\text { Score: } 0 / 3 / 0 / 0 / 0 / 0 / 0 / 0 / 0 / 0 / 0 / 0 / 0 / 0 \\
(3)\end{array}$ & normal \\
\hline
\end{tabular}

\section{Clinical data n- CoV 2019 CoV 458-469}

\begin{tabular}{|c|c|c|c|}
\hline $\begin{array}{l}\text { Animal } \\
\text { ID }\end{array}$ & Day $0-14$ & Day 42-46 & Necropsy notes \\
\hline C-4 & $\begin{array}{l}\text { Ruffled fur, slightly increased irregular } \\
\text { respirations } \\
\text { Score: } 0 / 0 / 0 / 5 / 10 / 5 / 0 / 0 / 0 / 0 / 0 / 0 / 0 / 0 / 0(20)\end{array}$ & $\begin{array}{l}\text { Slightly irregular respirations } \\
\text { Score:3/3/3/3 (12) }\end{array}$ & normal \\
\hline C-5 & $\begin{array}{l}\text { Reduced appetite, abdominal slightly } \\
\text { irregular breathing } \\
\text { Score :0/6/8/6/3/8/6/3/0/5/0/0/3/5/3 (56) }\end{array}$ & $\begin{array}{l}\text { Reduced appetite, slightly irregular } \\
\text { respirations } \\
\text { Score:0/0/6/0 (6) }\end{array}$ & normal \\
\hline C-6 & $\begin{array}{l}\text { Normal } \\
\text { Score: } 0 / 0 / 0 / 0 / 0 / 0 / 0 / 0 / 3 / 3 / 3 / 5 / 0 / 0(14)\end{array}$ & $\begin{array}{l}\text { Normal } \\
\text { Score:0/0/0/0 (0) }\end{array}$ & normal \\
\hline CD4-4 & $\begin{array}{l}\text { normal } \\
\text { Score: } 0 / 0 / 0 / 0 / 0 / 0 / 0 / 0 / 3 / 3 / 0 / 0 / 0 / 0 / 0(6)\end{array}$ & $\begin{array}{l}\text { normal } \\
\text { Score: } 0 / 0 / 0 / 0(0)\end{array}$ & normal \\
\hline CD4-5 & $\begin{array}{l}\text { Reduced appetite } \\
\text { Score: } 0 / 3 / 5 / 5 / 3 / 0 / 5 / 3 / 0 / 0 / 5 / 0 / 0 / 3 / 0(32)\end{array}$ & $\begin{array}{l}\text { normal } \\
\text { Score:0/0/0/0 (0) }\end{array}$ & normal \\
\hline CD4-6 & $\begin{array}{l}\text { normal } \\
\text { Score:0 /0/0/0/0/0/0/0/0/0/5/0/0/0/0 (5) }\end{array}$ & $\begin{array}{l}\text { normal } \\
\text { Score:0/0/0/0 (0) }\end{array}$ & normal \\
\hline CD8-4 & $\begin{array}{l}\text { Reduced appetite, increased irregular } \\
\text { abdominal respirations } \\
\text { Score:0/3/8/6/6/3/8/5/3/5/3/5/3/0/0 (58) }\end{array}$ & $\begin{array}{l}\text { Normal } \\
\text { Score: } 0 / 0 / 0 / 0(0)\end{array}$ & normal \\
\hline CD8-5 & $\begin{array}{l}\text { Reduced appetite, increased abdominal } \\
\text { respirations } \\
\text { Score:0/3/8/8/3/3/0/0/0/3/0/0/3/0/0 (31) }\end{array}$ & $\begin{array}{l}\text { normal } \\
\text { Score: } 0 / 0 / 0 / 0(0)\end{array}$ & normal \\
\hline CD8-6 & $\begin{array}{l}\text { Reduced appetite, increased respirations } \\
\text { Score: } 0 / 3 / 0 / 5 / 5 / 0 / 0 / 0 / 0 / 0 / 3 / 0 / 3 / 0 / 0(19)\end{array}$ & $\begin{array}{l}\text { Reduced appetite } \\
\text { Score:0/3/0/0 (3) }\end{array}$ & normal \\
\hline CD4/8-4 & $\begin{array}{l}\text { increased abdominal respirations, ruffled fur, } \\
\text { reduced appetite } \\
\text { Score: } 0 / 5 / 5 / 15 / 5 / 5 / 0 / 0 / 0 / 0 / 0 / 0 / 0 / 0 / 0(30)\end{array}$ & $\begin{array}{l}\text { normal } \\
\text { Score:0/0/0/0 (0) }\end{array}$ & normal \\
\hline CD4/8-5 & $\begin{array}{l}\text { Reduced appetite, ruffled fur, increased } \\
\text { irregular abdominal respirations } \\
\text { Score: 0/8/8/10/5/8/10/10/3/5/5/5/3/0/0 (80) }\end{array}$ & $\begin{array}{l}\text { Normal } \\
\text { Score: } 0 / 0 / 0 / 0(0)\end{array}$ & normal \\
\hline CD4/8-6 & $\begin{array}{l}\text { Reduced appetite, increased irregular } \\
\text { respirations, pale appearance } \\
\text { Score: } 0 / 6 / 5 / 15 / 13 / 13 / 13 / 15 / 6 / 3 / 5 / 5 / 3 / 0 / 0 \\
(102)\end{array}$ & $\begin{array}{l}\text { normal } \\
\text { Score: } 0 / 0 / 0 / 0\end{array}$ & normal \\
\hline
\end{tabular}




\section{SARS-CoV-2 neutralization}

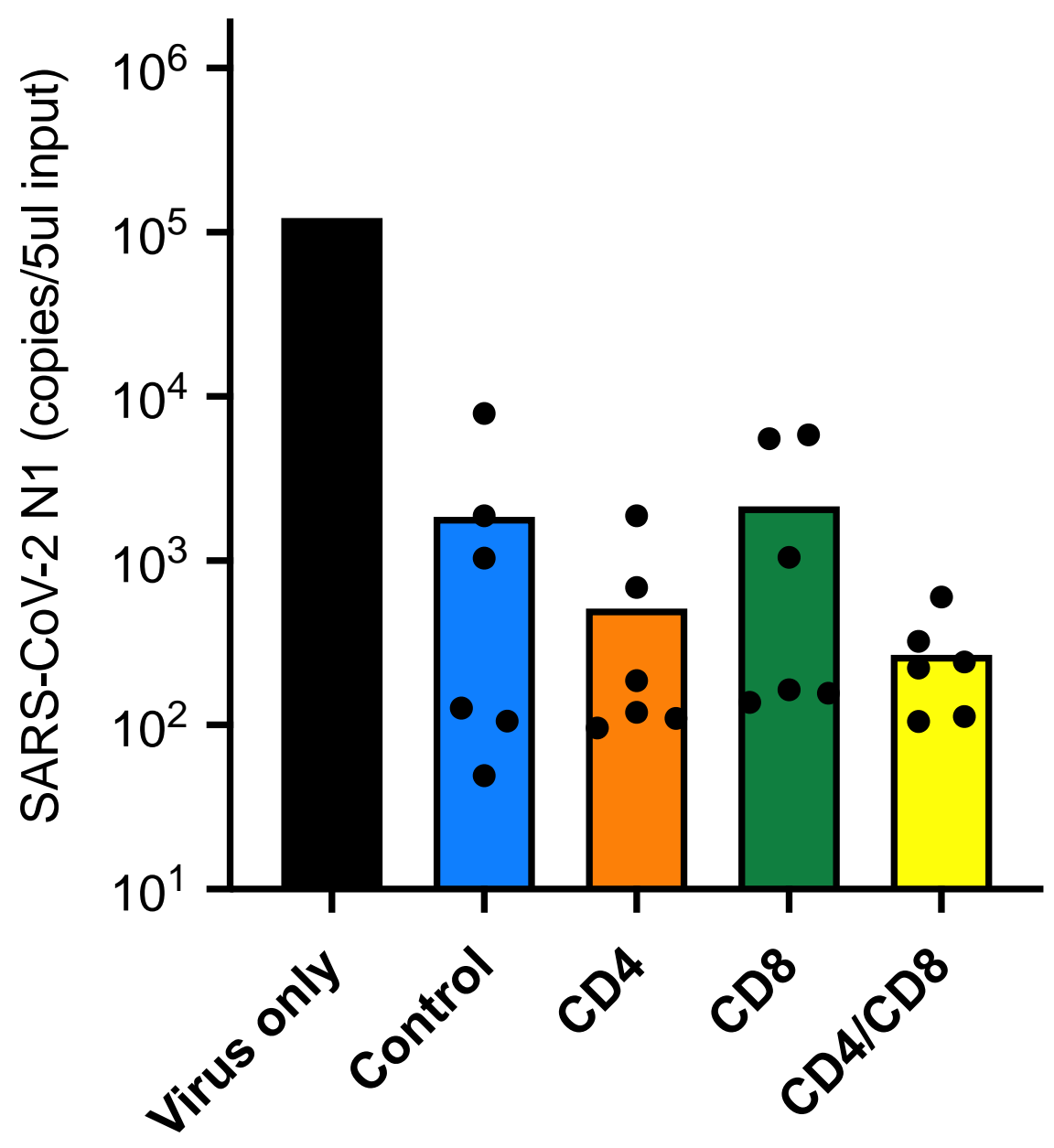

SARS-CoV-2 neutralization assay with live coronoavirus. Day 28 post-infection sera from all NHP were diluted 1:20 and tested for neutralization of SARS-CoV-2. Each dot represents the result from an individual macaque. 
Supplementary data Fig. 5a. CD4+ T cell staining in spleens.

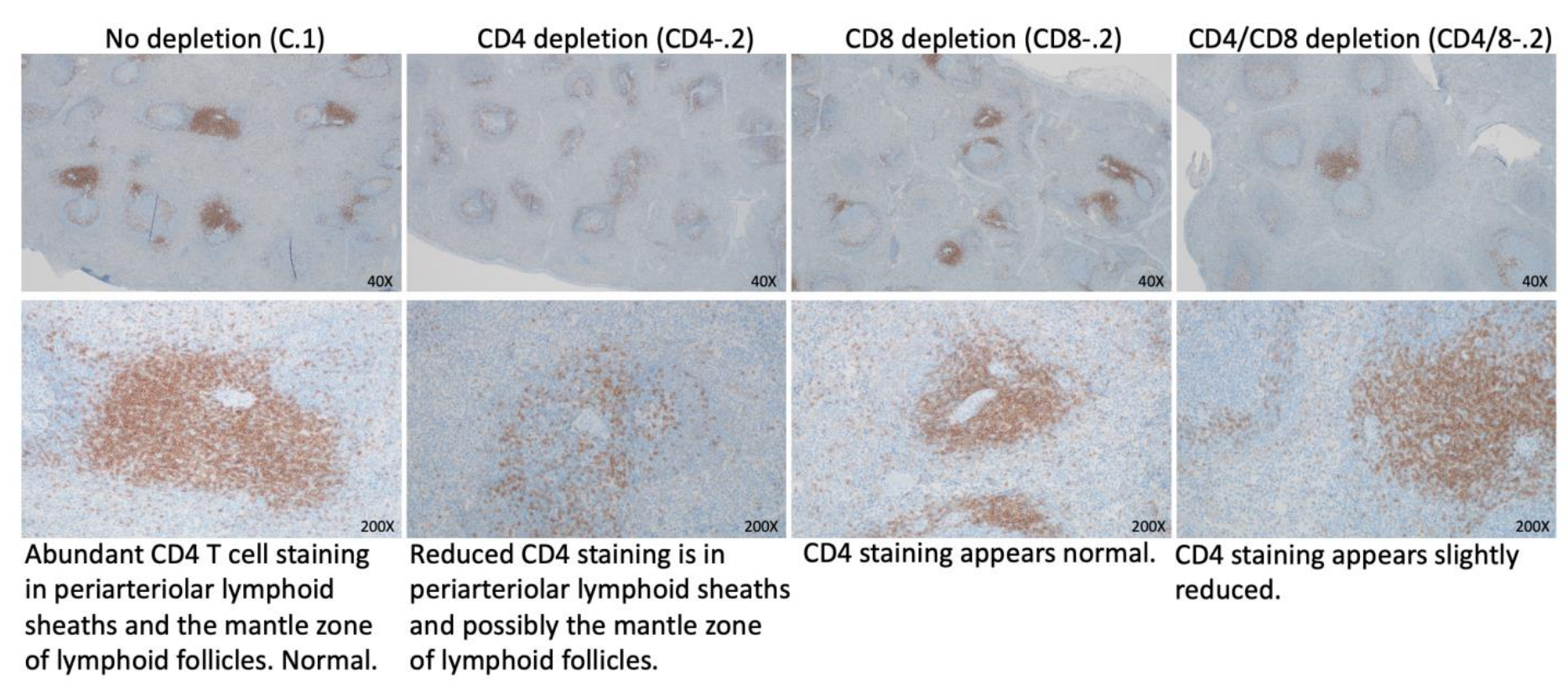

\section{Supplementary data Fig. 5b. CD8+ T cells in spleen}

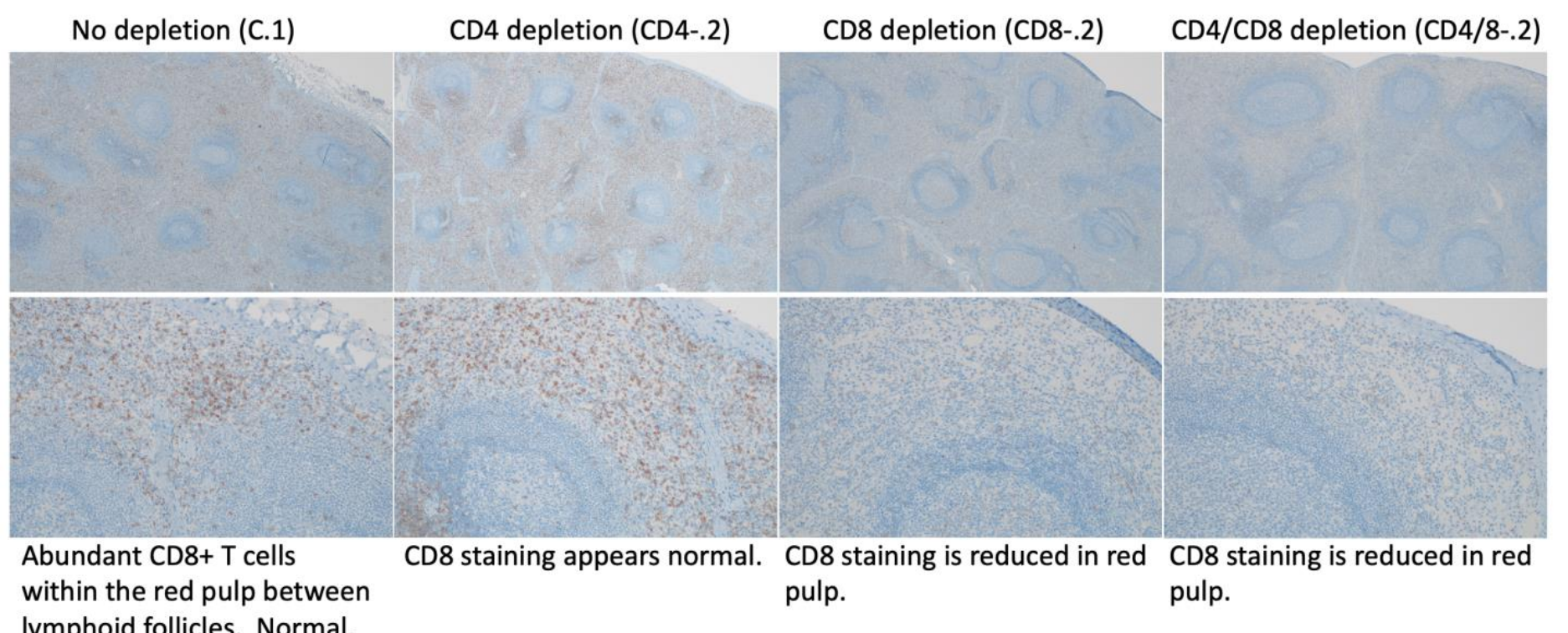




\section{Supplemetary Figure 6. IP-10 levels in broncho-alveolar lavage fluids.}
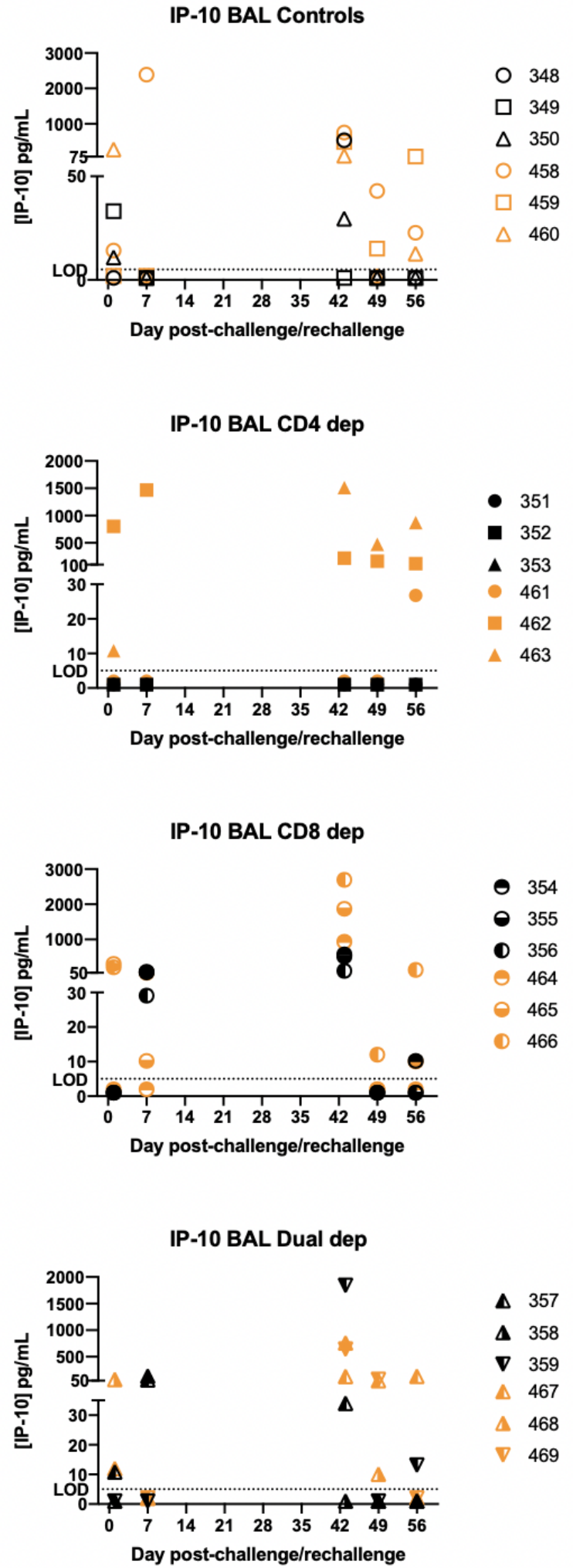